This item was submitted to Loughborough's Research Repository by the author.

Items in Figshare are protected by copyright, with all rights reserved, unless otherwise indicated.

\title{
Economic and environmental impact of lead-acid batteries in grid-connected domestic PV systems
}

PLEASE CITE THE PUBLISHED VERSION

http://dx.doi.org/10.1016/j.apenergy.2012.11.016

PUBLISHER

(C) Elsevier Ltd.

VERSION

AM (Accepted Manuscript)

LICENCE

CC BY-NC-ND 4.0

\section{REPOSITORY RECORD}

McKenna, Eoghan, Marcelle McManus, Sam Cooper, and Murray Thomson. 2019. "Economic and Environmental Impact of Lead-acid Batteries in Grid-connected Domestic PV Systems". figshare. https://hdl.handle.net/2134/11429. 
This item was submitted to Loughborough's Institutional Repository (https://dspace.lboro.ac.uk/) by the author and is made available under the following Creative Commons Licence conditions.

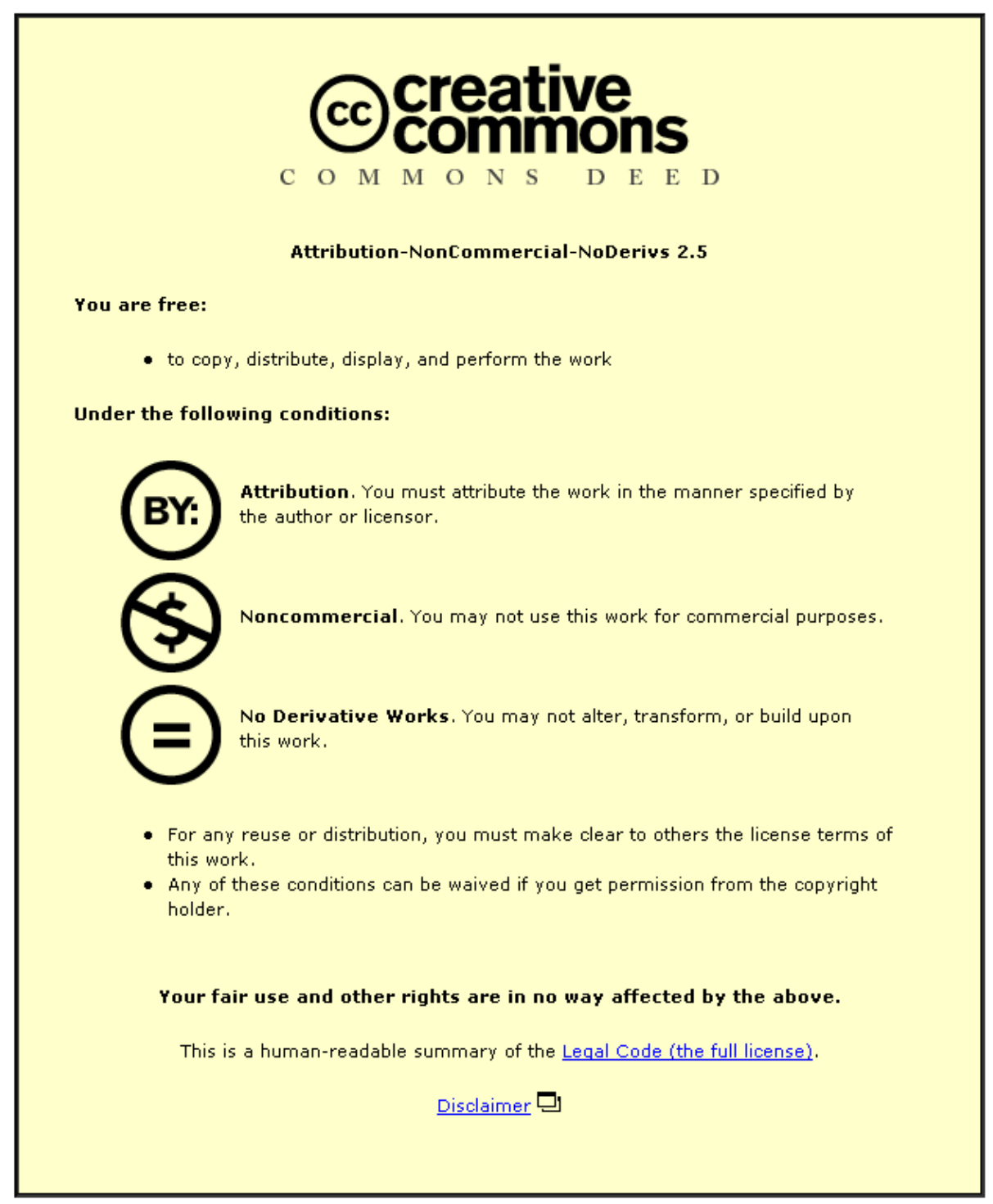

For the full text of this licence, please go to: http://creativecommons.org/licenses/by-nc-nd/2.5/ 


\section{Economic and environmental impact of lead-acid batteries in grid-connected domestic PV systems}

3

\author{
Eoghan McKenna ${ }^{\text {**}}$, Marcelle McManus ${ }^{b}$, Sam Cooper ${ }^{b}$, and Murray Thomson a \\ a Centre for Renewable Energy Systems Technology (CREST), \\ School of Electronic, Electrical and Systems Engineering, \\ Loughborough University, Leicestershire, LE11 3TU, UK \\ b Department of Mechanical Engineering, \\ University of Bath, Bath, BA2 7AY, UK \\ * Corresponding author: e.j.mckenna@lboro.ac.uk, + 44 (0) 7958531842 \\ $6^{\text {th }}$ November 2012
}

\section{Abstract}

Occupants of dwellings with grid-connected photovoltaic (PV) systems can often benefit financially from exporting electricity to the grid. When export prices are lower than import prices, however, occupants are incentivised to time-shift demand in order to avoid exports and reduce imports. To maximise this potential financial benefit, the addition of batteries to the PV system has been proposed to take advantage of the specific commercial opportunity presented to the occupant of trading exported power during the day for imported power during the evening. This paper therefore assesses the economic and environmental impact of the use of lead-acid batteries in grid-connected PV systems under current feed-in tariff arrangements in the UK. The development of a lead-acid battery model is described, which is used to simulate hypothetical power flows using measured data on domestic PV systems in the UK. The simulation results indicate that the net benefit of the battery is negative, even when considering an idealised lossless battery. When realistic energy losses and lifetimes are accounted for, the financial loss for the systems considered here can approach $£ 1000 /$ year. The environmental impact of the use and production of the lead-acid battery is also described, and also found to be negative, further strengthening the argument against the use of lead-acid batteries in domestic grid-connected PV systems.

Keywords: lead-acid battery; PV system; feed-in tariff; environmental impact. 


\section{Introduction}

35 There is considerable interest in the use of electrical storage technology in low36 carbon power systems. At the national transmission system level, large-scale 37 storage could help system balancing with high penetrations of wind power [1]. At 38 the level of the local distribution network, intelligent management of battery 39 charging in electric vehicles could help prolong the use of existing network 40 assets, avoiding unnecessary costs [2]. At the domestic level, the use of batteries 41 in grid-connected photovoltaic (PV) systems has been proposed for the purposes 42 of minimising grid exports [3], improving consumer economics by exploiting 43 retail electricity tariffs with variable pricing [4], and increasing self-consumption 44 with feed-in tariffs [5].

45 The use of batteries in grid-connected domestic PV systems mentioned in the 46 previous paragraph is investigated in this paper. An economic and 47 environmental impact analysis is presented for the use of lead-acid batteries in 48 PV systems under current feed-in tariff arrangements in the UK, where the 49 specific commercial opportunity for the occupant is in reducing exported power 50 during the day, and trading this for a reduction in imported power during the 51 evening.

52 The present work builds on previous work by Jenkins [3,6] on the impact and 53 ageing of lead-acid batteries in grid-connected domestic PV systems in the UK. 54 The present work, however, differs considerably from Jenkins' work: the 55 economic impact of the battery for the occupants takes into account current UK 56 feed-in tariff arrangements, recorded data is used from multiple domestic 57 dwellings with PV, a novel battery model is developed, and the environmental 58 impacts of the battery are considered. This work also builds on previous work by 59 one of the authors on the environmental impact of battery production [7], by also 60 considering the in-use environmental impacts of the battery for such 61 applications.

62 The approach taken in this paper is to develop a model of a lead-acid battery, 63 which is applied to recorded data from UK dwellings with PV systems. The 64 model is used to simulate hypothetical power flows for the PV system with 65 battery. Section 3 describes the development of the battery model, and the 66 method used to calculate the simulated power flows, cost benefits, and 67 environmental impacts associated with the battery. Section 4 then presents and 68 discusses the results of the economic and environmental analysis, with section 5 69 providing the concluding remarks. 


\section{Feed-in tariffs and the financial benefits in time-shifting demand}

This paper considers domestic grid-connected PV systems on a current UK feedin tariff, which consists of a generation price $(21.0 \mathrm{p} / \mathrm{kWh}$ at the time of writing) paid for generated units, and an export price of $3.2 \mathrm{p} / \mathrm{kWh}$ paid for exported units [8]. An import price of $11.8 \mathrm{p} / \mathrm{kWh}$ has been assumed, which is a typical value for a domestic consumer on a 'standard' flat-rate demand tariff [9].

In this context, occupants with PV systems can benefit financially by using electricity generated by their PV rather than exporting it to the grid [10]. Occupants could typically achieve this by changing their behaviour or routines in order to shift their demand to the middle of the day when their PV is generating [11], for example by eating a hot meal at lunch rather than dinner, or with the help of technology such as timers, that can delay when appliances are switched on.

A further option available to the occupants, considered here, is the use of battery storage [12]. In the UK context, the battery is charged during the day using cheap surplus PV generation, and discharged during the evening and night, to avoid the expensive imports from the grid [3]. Note that battery systems of this type are commercially available for this purpose in the UK $[13,14]$.

\section{Method}

This section describes a novel method for developing a realistic lead-acid battery model. The battery model is empirical, using existing work as input data - the novelty lies in how this data is combined in order to create a realistic model. The authors note that there are numerous other approaches to modelling lead-acid batteries in PV systems and refer interested readers to [3,15-17].

The model estimates the battery efficiency under varying rates of charge and discharge, as well as varying states of charge. Operational energy losses are quantified using the concepts of voltage efficiency and coulombic, or charge, efficiency. The overall energy efficiency of the battery can be viewed as the product of the battery's voltage and coulombic efficiencies.

The voltage efficiency reflects the fact that charge is removed from a battery at low voltage, while charge is added to it at a higher voltage. This difference in charging and discharging voltage inevitably results in energy losses. 
103 Coulombic efficiency reflects the fact that more charge has to be put into the 104 battery than it is possible to subsequently remove. Coulombic efficiency, in 105 particular, is adversely affected by rapid charging and rapid discharging. Due to 106 the 'peaky' nature of domestic dwelling demand [18], losses associated with rapid 107 discharging will be particularly significant for the application considered in this 108 paper. Finally, both voltage and coulombic efficiency are also reduced at high 109 states of charge [19].

110 The model is based on the data sheet of a BP Solar 'PVstor' valve-regulated lead111 acid battery [20], which is designed for use in stand-alone PV systems. While 112 these batteries may not be optimised for grid-connected systems, nonetheless it 113 is assumed that batteries for these two applications will have broadly similar 114 characteristics. Three battery sizes from the PVStor range are considered, 115 detailed in Table 1. A $48 \mathrm{~V}$ battery system has been chosen, as this is the voltage 116 level specified for the chosen inverter (described in section 3.7).

117 Table 1 - Details of the batteries used in the study.

\begin{tabular}{|l|l|l|l|}
\hline & Battery option 1 & Battery option 2 & Battery option 3 \\
\hline Capacity & $210 \mathrm{Ah}$ & $430 \mathrm{Ah}$ & $570 \mathrm{Ah}$ \\
\hline Voltage & $48 \mathrm{~V}$ & $48 \mathrm{~V}$ & $48 \mathrm{~V}$ \\
\hline Energy capacity & $10.08 \mathrm{kWh}$ & $20.64 \mathrm{kWh}$ & $27.36 \mathrm{kWh}$ \\
\hline $\begin{array}{l}\text { Estimated battery } \\
\text { cost }\end{array}$ & $£ 1280$ & $£ 2621$ & $£ 3475$ \\
\hline Inverter size & $2.02 \mathrm{~kW}$ & $4.13 \mathrm{~kW}$ & $5.47 \mathrm{~kW}$ \\
\hline $\begin{array}{l}\text { Estimated inverter } \\
\text { cost }\end{array}$ & $£ 1222$ & $£ 2502$ & $£ 3316$ \\
\hline
\end{tabular}




\subsection{Battery charge and discharge voltage}

120 Figure 1A has been adapted from the manufacturer's data sheet and shows

121 battery cell voltage as a function of state of charge for varying rates of charge 122 and discharge. The top four lines represent the charge voltages, while the bottom 123 four represent discharge voltages. The different currents are indicated by ' $\mathrm{C}$ ' 124 values. C100 refers to a constant current that would fully discharge the battery 125 over a period of 100 hours. For a 430 Ah battery, C100 is equal to $4.3 \mathrm{~A}$, and C10 126 is equal to $43 \mathrm{~A}$. For a $210 \mathrm{Ah}$ battery, C100 is $2.1 \mathrm{~A}$, and so on. $\mathrm{C}$ values have 127 the same magnitude for both charging and discharging. The general relationship 128 is as follows:

$$
C_{n}=\frac{C_{\text {nominal }}}{n}
$$

Equation 1

130 Where:

131

$n$ - discharge time (hours).

132

$C_{n}-\mathrm{C}^{\prime}$ value for a discharge time $n(\mathrm{~A})$.

133

$C_{\text {nominal }}-$ nominal capacity of the battery.

134

135

136

137

138

139

140

141

142

143

144

145

146

147

148

149

150

151

\subsection{Voltage efficiency}

It can be seen from Figure 1A that, for a given state of charge, the rate of discharge has less effect on the voltage compared to the rate of charge. As a result, in the model, the voltage efficiency is applied to the charge phase and not the discharge phase. The model therefore estimates the voltage efficiency as a function of the state of charge and rate of charge. Figure 1B shows the voltage efficiency which is estimated here as the ratio of the discharge voltage over the charge voltage, taken at the same rate of charge and discharge. As expected, efficiencies tend to be lower at high state of charge, and high currents.

\subsection{Coulombic efficiency}

The effect of state of charge on coulombic efficiency is estimated from Stevens [19], which gives empirical data for coulombic efficiency at different states of charge for a valve regulated lead-acid battery used in PV applications. Coulombic efficiency is defined here as amp-hours output over amp-hours input. This data is reproduced in Figure 2A, and shows the reduction in coulombic efficiency associated with incremental changes in battery state of charge. Stevens only gives data for states of charge above $70 \%$, though this is sufficient for this battery model because a minimum state of charge of $60 \%$ is used. 
152 Figure 2A shows that, while coulombic efficiency is high for states of charge 153 below $70 \%$, it decreases considerably as the battery reaches a fully charged state. 154 Intuitively, this reflects the fact that, as the battery is charged, it becomes 155 increasingly difficult to charge it further. Note that Stevens' experiment only 156 tested a single rate of charge and discharge, in this case a value close to the 157 battery's nominal discharge rate. In the model, as a matter of choice, the 158 coulombic efficiency as a function of state of charge is applied to the battery 159 charging cycle, though it could equally have been applied on the discharge cycle.

160 The effect of the rate of discharge is considered independently. This is estimated 161 from data from the manufacturer describing the available battery capacity (in $162 \mathrm{Ah})$ as a function of varying rates of discharge [20]. Table 2 reproduces the data 163 for the $430 \mathrm{Ah}$ battery. This shows that the capacity available is decreased if the 164 battery is discharged at higher currents. A second, independent coulombic 165 efficiency is therefore estimated as the ratio of the capacity available at a given 166 discharge rate compared to the capacity available at nominal discharge rate 167 (C100). This is shown as a function of discharge current in Figure 2B for the 168 three battery sizes considered here. In the model, this coulombic efficiency is 169 applied to the discharge phase. When modelled in this way, the round trip 170 efficiency for a full charge followed by a full discharge at C100 is approximately $17173 \%$. For C10, the round trip efficiency is $44 \%$. Note that these round-trip 172 efficiencies are for illustration only - the operation of the battery in the model 173 does not use full discharge cycles.

174 Table 2 - Discharge characteristics of the $430 \mathrm{Ah}$ battery at varying rates of discharge at $25^{\circ} \mathrm{C}$.

\begin{tabular}{|c|c|c|c|c|}
\hline & $\begin{array}{c}\text { Hours for full } \\
\text { discharge }\end{array}$ & Discharge current (A) & $\begin{array}{c}\text { Capacity available } \\
(\mathrm{Ah})\end{array}$ & $\begin{array}{c}\text { Coulombic } \\
\text { efficiency }\end{array}$ \\
\hline $\mathrm{C}_{0.5}$ & 0.5 & 194.00 & 97 & $23 \%$ \\
\hline $\mathrm{C}_{1}$ & 1 & 110.00 & 110 & $26 \%$ \\
\hline $\mathrm{C}_{2}$ & 2 & 64.00 & 128 & $30 \%$ \\
\hline $\mathrm{C}_{3}$ & 3 & 50.67 & 152 & $35 \%$ \\
\hline $\mathrm{C}_{4}$ & 4 & 39.50 & 158 & $37 \%$ \\
\hline $\mathrm{C}_{5}$ & 5 & 33.20 & 166 & $39 \%$ \\
\hline $\mathrm{C}_{6}$ & 6 & 29.83 & 179 & $42 \%$ \\
\hline $\mathrm{C}_{7}$ & 7 & 27.29 & 191 & $44 \%$ \\
\hline $\mathrm{C}_{8}$ & 8 & 27.13 & 217 & $50 \%$ \\
\hline $\mathrm{C}_{9}$ & 9 & 26.11 & 235 & $55 \%$ \\
\hline $\mathrm{C}_{10}$ & 10 & 25.50 & 255 & $59 \%$ \\
\hline $\mathrm{C}_{25}$ & 25 & 12.32 & 308 & $72 \%$ \\
\hline $\mathrm{C}_{50}$ & 50 & 7.22 & 361 & $84 \%$ \\
\hline $\mathrm{C}_{100}$ & 100 & 4.30 & 430 & $100 \%$ \\
\hline
\end{tabular}




\subsection{Calculation of power flows}

177 The battery efficiencies described above are then applied to the system shown in

178 Figure 3. This presents a one-line diagram showing the major electrical 179 components of the PV system with battery storage that is modelled in this paper.

180 A description of the variables used is provided in Table 3. The PV system shown 181 here is fully metered, as it includes an export meter as well as a generation 182 meter.

183 Table 3 - Description of variables.

\begin{tabular}{|l|l|}
\hline Variable & Description \\
\hline$P_{p V}$ & PV generation (kW). \\
\hline$P_{e}$ & PV output exported to grid (kW). \\
\hline$P_{i}$ & $\begin{array}{l}\text { Electricity demand imported from the grid } \\
\text { (kW). }\end{array}$ \\
\hline$P_{n e t}=P_{e}-P_{i}$ & Dwelling's net power flow (kW). \\
\hline$P_{d}=P_{p v}-P_{n e t}$ & Consumer electricity demand (kW). \\
\hline$P_{\text {bat }}$ & Power from battery (kW). \\
\hline$I_{\text {bat }}$ & Current from battery (A). \\
\hline$V_{\text {bat }}$ & Battery voltage (V). \\
\hline SOC & Battery state of charge (\%). \\
\hline$\eta_{\text {inv }}$ & Battery inverter efficiency. \\
\hline$\eta_{v o l t a g e}$ & Battery voltage efficiency. \\
\hline$\eta_{\text {SOC }}$ & $\begin{array}{l}\text { Battery coulombic efficiency due to state of } \\
\text { charge. }\end{array}$ \\
\hline$\eta_{\text {dischage }}$ & $\begin{array}{l}\text { Battery coulombic efficiency due to rate of } \\
\text { discharge. }\end{array}$ \\
\hline$t$ & Time (hours). \\
\hline
\end{tabular}

185 Note that the battery is connected via a DC-AC converter to the consumer unit 186 (distribution board), and not connected via DC to the PV, as for example is 187 proposed by Braun et al. [5]. This is for practical considerations, as the PV and 188 battery have different DC voltages and separate converters are more likely to be 189 'off the shelf' components, as well as to avoid losses in the battery before the 190 units generated by the PV are metered by the generation meter. Note that a 191 technical comparison of different system configurations is out of scope of this 192 paper.

193 Battery power flows are then calculated as follows. The battery is charged when 194 the following conditions are met:

$$
P_{p v}>P_{d} \text { and } S O C<S O C_{\max }
$$


196 The battery is disconnected when either the minimum state of charge $S O C_{\text {min }}$ $197(60 \%)$ or maximum state of charge $S O C_{\max }(100 \%)$ is reached. This constraint has 198 been imposed in order to ensure maximum battery life as per the manufacturer's 199 recommendations [20].

200 The battery charging current is then calculated as:

$$
I_{b a t}=\frac{\eta_{i n v}\left(P_{d}-P_{p v}\right)}{V_{b a t}}
$$

201

Equation 2

202 Charging current is limited to C13 (33 A for a 430 Ah battery), based on battery 203 manufacturer's recommendations [20].

204 The charge entering the battery $\left(Q_{\text {charge }}\right)$ is then calculated by:

$$
Q_{\text {charge }}=-\eta_{\text {voltage }} \eta_{\text {Soc }} I_{\text {bat }} t
$$

205

Equation 3

206 The minus sign is necessary because charging currents are taken as negative in 207 the model.

208 State of charge in time interval $i$ is then:

$$
\operatorname{SOC}(i)=\operatorname{SOC}(i-1)+Q_{\text {charge }}(i)
$$

209

Equation 4

210 The battery is discharged when the following conditions are met:

$$
P_{p v}<P_{d} \text { and } S O C>S O C_{\min }
$$


212 In which case the battery discharge current is given by:

$$
I_{b a t}=\frac{P_{b a t}}{\eta_{\text {inv }} V_{b a t}}
$$

213

Equation 5

214 Discharge current is limited to C5 (86 A for a $430 \mathrm{Ah}$ battery), again based on 215 manufacturer's recommendations. The charge leaving the battery $\left(Q_{\text {discharge }}\right)$ is 216 then given by:

$$
Q_{\text {discharge }}=\frac{I_{\text {bat }} t}{\eta_{\text {discharge }}}
$$

218 State of charge in time interval $i$ is given by:

$$
\operatorname{SOC}(i)=\operatorname{SOC}(i-1)-Q_{\text {discharge }}(i)
$$

\subsection{Calculation of economic benefit of battery operation}

221 The operation of the battery will reduce exports and imports. The reduction in 222 exports is an opportunity cost to the system owner, while the reduction in 223 imports is a benefit due to avoided costs. The economic benefit associated with 224 the battery in time interval $i, m_{\text {net }}(i)$, is calculated by:

$$
m_{\text {net }}(i)=\Delta m(i)-\Delta c(i)
$$

226 Where $\Delta m(i)$ is the change in income to the occupant in time interval $i$ associated 227 with the battery. This is the difference between the income to the occupant 228 associated with generation and export payments with the battery and the 229 equivalent income without the battery. For example, if the battery reduced 230 exports in time interval $i$, then $\Delta m(i)$ would be negative.

$231 \Delta c(i)$ is the change in costs to the occupant in time interval $i$ associated with the 232 battery. This is the difference between the cost of electricity consumed within the 233 dwelling with the battery compared to the equivalent cost of electricity without 234 the battery. For example, if the battery reduced imports in time interval $i$, then $235 \Delta c(i)$ would be negative, as costs would be reduced.

236 The estimate of the total economic benefit of the battery (not including 237 equipment costs) is then given by the sum of $m_{\text {net }}$ over the course of a whole year 238 for the dwellings described in the following section. 


\subsection{Description of data used in the analysis}

240 In Figure 3, power flows denoted with an asterisk indicate where recorded data 241 on domestic dwellings with installed PV in the UK has been used from the 242 Photovoltaic Domestic Field Trial ("DFT") [21]. The battery model is used to 243 simulate hypothetical power flows given the addition of a battery to the systems. 244 In the model, the dwelling demands and PV generation are unchanged from 245 those of the DFT systems. The resolution of the data is 5 minutes.

246 The study uses data from two of the Domestic Field Trail's sites. The first site 247 consists of data from 22 dwellings, and the second site consists of data from 15 248 dwellings. Annual irradiances for the two sites were $894.7 \mathrm{kWh} / \mathrm{m}^{2}$, and $249892.8 \mathrm{kWh} / \mathrm{m}^{2}$, which are quite typical for the UK [22].

250 Note that the sizes of PV systems installed in the dwellings considered here 251 range between $1.5 \mathrm{~kW}_{\text {peak }}$ and $3.29 \mathrm{~kW}_{\text {peak, }}$, while recent installations in the UK 252 are closer to $4 \mathrm{~kW}_{\text {peak. }}$. The applicability of the results to more modern systems 253 will be discussed in the results.

\section{$254 \quad$ 3.7. Battery inverter}

255 The battery inverter is based on the SMA Sunny Backup 5000 [13], which 256 includes battery charge regulator and power electronic converter. The efficiency 257 of the inverter is modelled on the efficiency curve provided in this product's 258 manual. The inverter has a peak efficiency of $95.4 \%$ and efficiency of more than $25991 \%$ throughout most of its operating range. Note that this efficiency applies to 260 charging as well as discharging. The inverters are sized for the maximum 261 discharge current of the batteries multiplied by the battery voltage, giving the 262 inverter sizes shown in Table 1. 


\subsection{Cost and lifetime of equipment}

264 Costs were estimated as the cost of the equipment (battery and battery inverter) 265 divided by its expected lifetime. Battery costs have been estimated at $\$ 200 / \mathrm{kWh}$ 266 from a Sandia National Laboratories Report [23]. The cost of the battery inverter 267 has been estimated at $£ 606 / \mathrm{kW}$, based on lowest of three quotes for 'SMA Sunny 268 Backup systems' produced from an internet search [24-26]. The Sunny Backup 269 has been chosen as it is a battery inverter that is currently commercially 270 available and designed for the purposes in hand. Table 1 shows the inverter sizes 271 for the three batteries considered here.

272 Inverter lifetime was assumed to be 10 years. Battery lifetime is estimated from 273 Jenkins' design equation, which estimates the useful lifetime for lead-acid 274 batteries in grid-connected residential PV systems as a function of the battery 275 size and usage [6], as follows:

$$
T=\frac{329.9 \times S}{E_{e}}
$$

277 Where:

$278 T$ - estimated battery lifetime (years).

$279 E_{e}-$ Annual exports available from the PV system (kWh/year).

$280 S$ - battery capacity $(\mathrm{kWh})$.

$281 \quad 3.9$. Environmental impact

282 The environmental impact is considered in two areas: production impacts, and 283 in-use impacts. For both of these, the analysis compares the impact associated 284 with adding a battery to the PV systems considered here, compared to the same 285 PV systems without battery. 
287 The production impact of lead acid batteries was determined by examining the 288 processes and materials contained within the battery. While a full Life Cycle 289 Assessment was not undertaken, a life cycle approach was taken, following the 290 ISO Standards [27,28]. This was done using SimaPro software, and was 291 originally described by McManus [7]. Three environmental issues have been 292 assessed; the impact on greenhouse gases (GHG), fossil fuel depletion, and metal 293 depletion. These were analysed using both IPCC data and the 'Recipe' LCA 294 methodology [29]. The work has focused on these three areas as previous 295 research has shown these are some of the major impact areas for battery use and 296 production [7]. In addition, GHG and fossil fuel depletion are major policy 297 drivers within the energy arena, and the impact of metal depletion has been 298 widely discussed as a potential area for concern associated with the use and 299 production of batteries [30].

300 The production impacts of lead-acid batteries per $\mathrm{kg}$ of battery weight in terms of 301 greenhouse gases, metal depletion, and fossil fuel depletion are $0.9 \mathrm{~kg} \mathrm{CO}_{2 \mathrm{eq}}$,

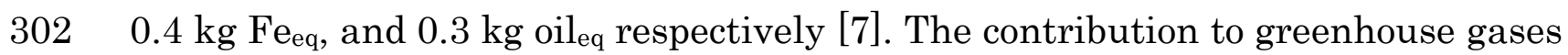
303 and fossil fuel is predominantly associated with the extraction and processing of 304 lead and the polypropylene used in the battery production. The contribution to 305 metal depletion is dominated by the lead within the battery. Note that this 306 approach assumes a mix of virgin and recycled materials is used in the battery 307 production, based current norms, as described by McManus [7].

\subsubsection{In-use impacts}

309 The in-use impact of the batteries is associated with the time-varying 310 environmental impact of grid-electricity [31]. From the perspective of the 311 national grid, the effect of adding a battery to a PV system (where previously 312 there was none) is to increase demand during the day, when the battery is 313 charging, and to decrease demand during the evening, when the battery is 314 discharging. These changes in demand throughout the course of the day will 315 result in corresponding changes in generation from fossil fuel plant. Moreover, 316 due to losses in the battery it can be expected that the increase in daytime 317 generation will be greater than the corresponding decrease in generation during 318 the evening, meaning that the battery will cause a net increase in fossil fuel 319 generation, with a resulting negative environmental impact. 
320 To calculate how the changes in demand throughout the day associated with 321 adding the battery to the PV system can be expected to result in changes in 322 generation from fossil fuel plant, data from the UK balancing mechanism reports 323 [32] was used to calculate the 'responsiveness' of gas and coal generation to 324 historic changes in demand for each five-minute period in 2009 to 2011. 325 Responsiveness here refers to the change in generation (in $\mathrm{kWh}$ ) that is 326 associated with a change in demand of $1 \mathrm{kWh}$.

327 For some time periods, a calculated responsiveness was uncharacteristically high 328 or low due to operators switching from one plant type to another. To compensate 329 for this effect, time periods were grouped into 144 sets (one for each hour of the 330 day for each two-month period of the year) and the weighted average 331 responsiveness of each plant type was calculated for each set. The average was 332 weighted by the absolute value of the change in total generation during each 333 time period (Equation 10). The resulting values for the responsiveness of coal 334 and gas plant are provided for reference in the Appendix.

$$
\overline{\left(\frac{\Delta P_{\text {gen }}}{\Delta P_{\text {total }}}\right)_{h}}=\sum_{i=h_{1}}^{h_{n}}\left[\left(\frac{\Delta P_{\text {gen }}(i)}{\Delta P_{\text {total }}(i)}\right)\left(\left|\Delta P_{\text {total }}(i)\right| / \sum_{i=1}^{h_{n}}\left|\Delta P_{\text {total }}(i)\right|\right)\right]
$$

336 Where:

$337 \overline{\left(\frac{\Delta P_{\text {gen }}}{\Delta P_{\text {total }}}\right)}$ - weighted average responsiveness of electricity generated by coal or gas 338 plant to unit changes in total electrical demand during the time periods in set $h$ $339 \quad\left(h_{1}\right.$ to $\left.h_{n}\right)$.

$340 \Delta P_{g e n}(i)$ - increase in average electrical power generation from gas or coal 341 generating plant during period $i$.

$342 \Delta P_{\text {total }}(i)$ - increase in average electrical power generation for whole electrical 343 grid during period $i$. 
344 The net change in generation from coal and gas is then calculated by multiplying 345 the weighted average responsiveness for gas and coal generation for each 5 346 minute time step by the net change in demand associated with adding the 347 battery to the PV system, and summing these over the entire year (Equation 11). 348 The net change in demand is determined by the battery model described above.

$$
\Delta E_{\text {gen }}=\sum_{i=1}^{n}\left[\Delta P_{\text {net }}(i) t\left(\overline{\frac{\Delta P_{\text {gen }}(l)}{\Delta P_{\text {total }}(l)}}\right)\right]
$$

350 Where:

$351 \Delta E_{g e n}$ - total net change in electricity generated from a type of generating plant 352 (gas or coal) for periods 1 to $n$.

$353 \Delta P_{n e t}(i)$ - net change in electrical demand in time period $i$ due to battery 354 operation (compared to PV system without battery).

355 Environmental impacts in the three areas considered for production are then 356 calculated by multiplying the total net changes in fossil fuel generation by the 357 impact data shown in Table 4. These values were calculated using a life cycle 358 approach using SimaPro software based on data from EcoInvent [33].

359 Table 4- Environmental impact of coal and gas generation.

\begin{tabular}{|l|c|c|c|}
\hline & $\begin{array}{l}\text { Climate Change } \\
\left(\mathbf{k g ~ C O}_{2 \mathrm{eq}}\right)\end{array}$ & $\begin{array}{l}\text { Metal depletion } \\
\left(\mathbf{k g ~ F e}_{\text {eq }}\right)\end{array}$ & $\left.\begin{array}{l}\text { Fossil fuel } \\
\text { depletion (kg oil }\end{array}\right)$ \\
\hline $\begin{array}{l}\text { For } \\
\text { electricity from gas } \\
\text { generation }\end{array}$ & 0.484 & $1.01 \times 10^{-3}$ & 0.198 \\
\hline $\begin{array}{l}\text { For } \\
\text { electricity from coal } \\
\text { generation }\end{array}$ & 1.08 & $3.99 \times 10^{-3}$ & 0.291 \\
\hline
\end{tabular}




\section{Results and Discussion}

\subsection{Battery operation for a single system over a single day}

363 The following results demonstrate the operation of the battery over a single day, 364 illustrating the battery's effect on the dwelling's net power flow, along with the resulting battery efficiencies, and the financial benefit to the occupant.

366 Figure 4A shows the demand profile for a single dwelling with a $3.29 \mathrm{kWp}$ PV 367 system on the $15^{\text {th }}$ June 2006 from the DFT dataset [21]. Note that the high 368 demand between 00:00 and 03:00 is likely due to electric water heating. The net 369 dwelling power flow to the grid is shown in Figure 4B with and without battery. 370 The battery starts the day at minimum state of charge because it was used the 371 previous evening, so the net power flow is unchanged throughout the morning. 372 At around 07:00, the PV generation starts to exceed the dwelling's demand, and 373 the battery starts charging. This reduces the net power flow to zero throughout most of the day. A small amount of power is still exported, however, when the surplus current from the PV exceeds the maximum charge current of the battery. At around 17:00, the dwelling demand exceeds PV generation, and the battery discharges. The net power flow reduces to zero, until approximately 23:00 when the battery reaches its minimum state of charge, and is disconnected.

379 Battery state of charge and efficiency is shown in Figure 5. The inverter 380 efficiency, not shown here, remains relatively high $(\sim 95 \%)$ throughout the day. 381 The battery charging efficiency and discharging efficiency are shown separately 382 in Figure 5B. As the battery state of charge increases during the day the 383 charging efficiency falls from $\sim 80 \%$ to $\sim 50 \%$. In the evening, the discharge 384 efficiency is determined by the rate of discharge, and drops below $50 \%$ on a 385 number of occasions.

386 The cost benefit of the battery operation is shown in Figure 6A. There is a 387 negative benefit throughout the middle of the day, associated with the 388 opportunity cost of reducing exports. This is followed by a positive benefit in the 389 evening as imported electricity is avoided. Figure $6 \mathrm{~B}$ shows the cumulative 390 benefit for the day, indicating that there was a modest benefit at the end of the 391 day of $\sim 10 \mathrm{p}$. Note this does not consider equipment costs, which are considered 392 in the following section.

\subsection{Cost benefit using realistic battery model}

394 The previous figures showed the effect of the battery over a single day for a 395 single dwelling, and this section extends this to include data from multiple 396 systems from the DFT dataset over the course of a whole year. Data for 37 397 individual dwellings is considered, corresponding to the two Domestic Field Trial 398 sites mentioned in section 3.6. 
399 Figure 7 shows how the realistic battery results in reductions in imports from 400 the grid and reductions in exports to the grid, for the systems and batteries 401 considered here. The reduction in imports are smaller than the reduction in 402 exports, due to losses in the battery. The gradient of the lines that pass through 403 the data points gives an indication of how many units of exported electricity are 404 used to provide one unit of avoided imported electricity. A least squares fit 405 through the data results in gradients of 2.14 (0.0482), 2.29 (0.0575), and 2.83 406 (0.0698) for the $570 \mathrm{Ah}, 430 \mathrm{Ah}$, and $210 \mathrm{Ah}$ batteries respectively (standard 407 errors in brackets). These gradients can be compared to the ratio of the import 408 price to the export price, $11.8 / 3.2=3.69$. Provided the gradient is smaller than 409 the import export price ratio, then the batteries can be expected to produce a 410 benefit in terms of savings on electricity bills.

411 Figure 8 shows the resulting annual benefits to the occupants of the dwellings 412 considered here, in terms of reduced costs of electricity, for the three sizes of 413 realistic batteries (black markers). The $\mathrm{x}$-axis shows annual exports for the PV 414 system without battery, as the main purpose of the battery is to reduce these 415 exports. The benefits are low - for the larger systems shown here, which are 416 comparable to modern $4 \mathrm{~kW}_{\text {peak }} \mathrm{PV}$ systems, the benefits of a battery might 417 amount to $\sim £ 30 /$ year.

418 The low benefits shown in Figure 8 are due to the battery inefficiencies which 419 are shown in Figure 9A. This shows annual round-trip efficiencies for the 420 different dwellings and battery size configurations. The round-trip efficiency is 421 calculated here as the total energy out of the battery inverter over the total 422 energy into the battery inverter. The mean round trip efficiency values are $423 \quad 39.1 \%$ for the $210 \mathrm{Ah}$ battery, $53.0 \%$ for the $430 \mathrm{Ah}$ battery, and $58.5 \%$ for the 424570 Ah battery.

425 Figure 10 shows annualised equipment costs for the realistic battery (black 426 markers), which can reach $\sim £ 1000 /$ year for the larger systems considered here. 427 The costs increase with available exports, which reflects the reduction in battery 428 lifetimes associated with battery wear, shown in Figure 9B. Systems with high 429 exports result in greater battery wear, and shorter lifetimes. For large systems, 430 comparable to modern $4 \mathrm{~kW}_{\text {peak }} \mathrm{PV}$ systems, a $570 \mathrm{Ah}$ battery has an expected 431 lifetime of 5.23 years, dropping to 1.93 years for a 210 Ah battery.

432 Figure 11 finally shows the resulting annual net benefit associated with the 433 realistic battery (black markers), which illustrates that there is no economic case 434 for the use of lead-acid batteries for the systems and specific purposes considered 435 here. 


\subsection{Cost benefit for a lossless battery}

437 Figure 9A illustrates that the operating conditions (specifically the charge and 438 discharge current limits) imposed here can result in battery efficiencies that are 439 very low indeed - to the point of being counter-productive for some systems. 440 Alternative operating conditions or strategies could therefore be considered in 441 order to optimise the system and reduce operational losses. In order to show that 442 the cost benefit results shown in Figure 11 are robust, however, and not 443 contingent on assumptions regarding battery efficiencies, equipment lifetimes, or 444 operating strategy, this section considers the cost benefit for a lossless battery 445 and inverter that are both $100 \%$ efficient.

446 In keeping with the assumption of a lossless battery, the battery is also assumed 447 not to experience any wear, and as such there is no effect on costs associated 448 with increasing annual exports (an indication of how much the battery is used). 449 Equipment lifetimes are therefore optimistic: 20 years for the battery, and 10 450 years for the inverter. This results in annualised costs of £186.2/year, $451 £ 381.2$ year, and £505.3/year for the $210 \mathrm{Ah}, 430 \mathrm{Ah}$, and $570 \mathrm{Ah}$ battery systems 452 respectively. These are illustrated for comparison alongside the realistic battery 453 costs in Figure 10. Note that the minimum state of charge for the lossless battery 454 is kept the same as that for the realistic battery $(60 \%)$.

455 The annual benefits for a perfectly efficient battery is shown in Figure 8 (grey 456 markers) alongside the benefits for the realistic battery, for the same dwellings 457 and battery sizes. For the lossless battery, it can be seen that the annual benefit 458 increases along with the available exports. Larger batteries increase the benefit 459 for larger systems with more exports, but have little effect on the smaller 460 systems. The data for benefits shows that a lossless battery can result in bill 461 savings of up to £110/year.

462 Figure 11 shows the resulting net benefit of the lossless battery (grey markers), 463 again alongside the equivalent net benefits of the realistic battery (black 464 markers). It is clear that the costs are considerably larger than the benefits for 465 all of the systems considered here, even when assuming a lossless battery with 466 optimistic lifetime estimates. The battery results in a net financial loss to the 467 occupant of around £100/year for the smallest lossless battery, increasing to over $468 £ 400 /$ year for the largest lossless battery considered here. It appears therefore 469 that there is no economic case for the use of lead-acid batteries for the systems 470 and specific commercial opportunity considered here, even for idealised lossless 471 batteries with optimistic lifetimes.

472 Note that these results ignore the cost of any routine maintenance, the cost of 473 installation, or indeed any discount rates applied to future benefits. If included, 474 these would obviously worsen the business case. 


\subsection{Environmental impact}

476 The production impacts for the batteries considered in this paper are shown in 477 Table 5. This production impact is spread over the lifetime of the batteries in 478 use, as estimated by Equation 9, and illustrated in Figure 9B.

479 Table 5 - Battery weights and production impacts.

\begin{tabular}{|c|c|c|c|c|c|c|}
\hline & & & & \multicolumn{3}{|c|}{ Production impacts } \\
\hline $\begin{array}{l}\text { Battery } \\
\text { Capacity } \\
\text { (Ah) }\end{array}$ & $\begin{array}{l}\text { Weight } \\
\text { per cell } \\
(\mathrm{kg})\end{array}$ & $\begin{array}{l}\text { Number of } \\
\text { cells in } \\
\text { battery }\end{array}$ & $\begin{array}{l}\text { Total } \\
\text { battery } \\
\text { weight } \\
\text { (kg) }\end{array}$ & $\begin{array}{l}\text { Climate } \\
\text { Change } \\
(\mathrm{kg} \mathrm{CO} \text { 2eq) }\end{array}$ & $\begin{array}{l}\text { Metal } \\
\text { depletion } \\
\left(\mathrm{kg} \mathrm{Fe}_{\mathrm{eq}}\right)\end{array}$ & $\begin{array}{l}\text { Fossil fuel } \\
\text { depletion } \\
\text { (kg oil } \text { eq })\end{array}$ \\
\hline 210 & 38 & 8 & 304 & 273.6 & 121.6 & 91.2 \\
\hline 420 & 29 & 24 & 696 & 626.4 & 278.4 & 208.8 \\
\hline 570 & 37 & 24 & 888 & 799.2 & 355.2 & 266.4 \\
\hline
\end{tabular}

480

481 Regarding the in-use impacts, the resulting change in fossil fuel generation over 482 the course of the day associated with the operation of a realistic 430 Ah battery 483 is shown in Figure 12. The values for the change in fossil fuel generation are 484 averages for all of the dwellings considered here over the course of the whole 485 year. It can be seen that the battery operation results in an increase in fossil fuel 486 generation during the day, and a decrease in the evening and night. It can be 487 seen that the area above zero is considerably greater than the area below zero, 488 which can be attributed to energy losses in the battery. It is interesting to note 489 that these results show that coal plant is more responsive to changes in demand 490 than gas plant.

491 The combined annual production and in-use impacts are now considered. Table 6 492 shows the combined impacts associated with adding a 430 Ah battery to a $4933.29 \mathrm{~kW}_{\text {peak }} \mathrm{PV}$ system. These results are comparable to the case of adding a 494 battery to a modern $4 \mathrm{~kW}_{\text {peak }}$ PV system. Not unexpectedly, metal depletion 495 impact is dominated by battery production, while climate change and fossil fuel 496 depletion impacts are dominated by battery use.

497 Table 6 - annual production and in-use impacts for 430 Ah battery with $3.29 \mathrm{~kW}$ peak PV system. Standard 498 deviations shown in brackets.

\begin{tabular}{|l|c|c|c|}
\hline & $\begin{array}{l}\text { Climate Change } \\
\left(\mathrm{kg} \mathrm{CO}_{2 \mathrm{eq}} / \mathrm{year}\right)\end{array}$ & $\begin{array}{l}\text { Metal depletion } \\
(\mathrm{kg} \mathrm{Fe} \text { eq } / \text { year) }\end{array}$ & $\begin{array}{l}\text { Fossil fuel depletion } \\
\left(\mathrm{kg} \mathrm{oil} \text { eq }_{\text {/year) }}\right.\end{array}$ \\
\hline Production impacts & $127.5(26.2)$ & $56.6(11.6)$ & $42.5(8.7)$ \\
\hline In-use impacts & $657.7(137.3)$ & $2.2(0.5)$ & $201.7(41.9)$ \\
\hline Total & 785.1 & 58.8 & 244.2 \\
\hline & & & $0.79(0.36)$ \\
\hline $\begin{array}{l}\text { In-use impacts } \\
\text { (lossless battery) }\end{array}$ & $5.09(2.35)$ & $0.0255(0.0188)$ & \\
\hline
\end{tabular}


500 The mean in-use impact values for the lossless 430 Ah battery are shown for

501 comparison in Table 6. As there are no energy losses with this battery, these 502 values can be interpreted as the impacts associated with the lossless time503 shifting of demand from the evening to the day. The difference between the in504 use impacts for the lossless battery and those for the realistic battery can 505 therefore be interpreted as the environmental impacts due to energy losses in 506 the battery, which are two orders of magnitude greater than those associated 507 with shifting demand from the evening to the day.

508 To put these results into perspective, the total annual climate change impact for 509 this battery has an equivalent impact in terms of $\mathrm{kg} \mathrm{CO} 2 \mathrm{eq} / \mathrm{year}$ as driving $5104362 \mathrm{~km}$ in a 'good' $(180 \mathrm{~g} \mathrm{CO} 2 \mathrm{eq} / \mathrm{km}) \mathrm{UK}$ petrol vehicle [33]. Alternatively, using 511 the same assumptions regarding responsiveness of fossil fuel plant as detailed in 512 section 3.9.2, it can also be equated to an average 2009 UK household 513 (4460 kWh/year) increasing annual electricity consumption by $946 \mathrm{kWh}$, an 514 increase of $21 \%$.

\section{$515 \quad$ 4.5. Target capital costs}

516 The theoretical maximum benefit to the occupants considered here is $11.8 \mathrm{p} / \mathrm{kWh}$ $517-3.2 \mathrm{p} / \mathrm{kWh}=8.6 \mathrm{p}$ per $\mathrm{kWh}$ of otherwise exported electricity. The mean annual 518 exports for the 37 systems considered here was $605 \mathrm{kWh} / \mathrm{year}$, which gives a 519 theoretical maximum benefit of $£ 52$ per dwelling per year. Assuming a modest 520 discount factor of $4 \%$ over 20 years, this results in a target up-front capital cost 521 of $£ 707$ for the battery system to break even. To put this into perspective, note 522 that the cheapest battery system considered here (210 Ah with optimistic 523 lifetimes) has an equivalent up-front capital cost of $£ 3296$.

\subsection{Comparison with feed-in tariffs from other countries}

525 The present study has considered the use of batteries with UK feed-in tariffs, 526 where the price differential between export price and import price is $8.6 \mathrm{p} / \mathrm{kWh}$ 527 as mentioned above. The results are, however, relevant more generally to other 528 countries with feed-in tariffs that have lower export prices than typical import 529 prices. 
530 In Germany, for example, a typical domestic system installed in 2011 will have 531 an export price of $\sim 29 \mathrm{c} € / \mathrm{kWh}$ and a 'self-consumption payment' of $\sim 17 \mathrm{c} € / \mathrm{kWh}$ 532 for electricity produced by the PV and consumed within the dwelling [34]. The

533 result is an 'effective export price' of $29 \mathrm{c€} / \mathrm{kWh}-17 \mathrm{c€} / \mathrm{kWh}=12 \mathrm{c€} / \mathrm{kWh}$, which 534 is $8 \mathrm{c} € / \mathrm{kWh}$ cheaper than a typical import price of $20 \mathrm{c} / \mathrm{kWh}$. This results in an 535 import export price ratio of $20 / 12=1.67$. As described in section 4.2 , the 536 minimum ratio needed to result in a benefit is 2.14 (for the 570 Ah battery). 537 Considering that Germany has a solar resource that is not dissimilar to that of 538 the UK [22], it would appear that the present study's conclusions concerning the 539 lack of business case for batteries in grid-connected PV systems is also applicable 540 to Germany.

541 The findings are also relevant to PV systems installed from late 2012 in the 542 Australian states of Queensland [35], Victoria [36], and Western Australia [37]. 543 These states have feed-in tariffs with export prices of $\sim 8 \mathrm{cAUD} / \mathrm{kWh}$, which is $54417 \mathrm{cAUD} / \mathrm{kWh}(\approx 10.93 \mathrm{p} / \mathrm{kWh})$ less than a typical import price of $25 \mathrm{cAUD} / \mathrm{kWh}$. 545 The import export price ratio is therefore 3.13, which is again lower than the UK 546 price ratio (3.69). The results of this paper are therefore also applicable to 547 Australian PV systems installed from late 2012 onwards.

548 Finally, note that this paper has only considered the economic benefit to the 549 occupant associated with the use of the battery given current feed-in tariff 550 arrangements. It is quite possible however that there are additional economic 551 benefits associated with this type of distributed storage, in particular to other 552 stakeholders e.g. system operator, distribution network operator. Quantifying 553 these additional benefits has been left for future research work to consider.

\section{5. Conclusions}

555 The addition of batteries to grid-connected domestic PV systems has been 556 examined for its ability to maximise the financial return of the system. The 557 purpose of the battery is to charge during the day using cheap surplus PV 558 generation, and to discharge during the evening to avoid expensive imports from 559 the grid. This paper has investigated the economic and environmental impact of 560 the use of lead-acid batteries in domestic PV systems under current UK feed-in 561 tariff arrangements. 
The results indicate that there is no economic case for the use of lead-acid

563 batteries for the systems considered here, even for idealised lossless batteries 564 with optimistic lifetimes. The realistic battery model developed here produced mean round trip efficiencies of $39.1 \%, 53.0 \%$, and $58.5 \%$ for $210 \mathrm{Ah}, 430 \mathrm{Ah}$, and $570 \mathrm{Ah}$ lead-acid batteries respectively. Unsurprisingly, when these efficiencies and realistic lifetimes are accounted for, the financial losses are considerably worse. For the batteries considered here, losses approaching $£ 1000 / y e a r$ can be expected for a $570 \mathrm{Ah}$ added to a $3.29 \mathrm{~kW}_{\text {peak }} \mathrm{PV}$ system.

The environmental impact of the production and use of lead-acid batteries for this purpose is also negative, and comparable to driving over $4000 \mathrm{~km}$ per year in a 'good' UK average petrol car. This further strengthens the argument against the use of such batteries for these purposes.

\section{Acknowledgements}

This work was supported by the Engineering and Physical Sciences Research Council, UK, within the HiDEF Supergen project (EP/G031681/1). The principal author was also supported by Secure Meters (UK) Ltd. The authors would also like to express their gratitude to the reviewers of this paper for their helpful feedback.

\section{References}

581 [1] P. Grünewald, T. Cockerill, M. Contestabile, P. Pearson, The role of large 582 scale storage in a GB low carbon energy future: Issues and policy challenges, 583 Energy Policy 39 (2011) 4807-4815.

584 [2] G. Strbac, C.K. Gan, M. Aunedi, V. Stanojevic, P. Djapic, J. Dejvises, P. Mancarella, A. Hawkes, D. Pudjianto, Benefits of Advanced Smart Metering for Demand Response based Control of Distribution Networks, (2010).

587 [3] D. Jenkins, J. Fletcher, D. Kane, Model for evaluating impact of battery 588 storage on microgeneration systems in dwellings, Energy Conversion and 589 Management 49 (2008) 2413-2424.

590 [4] G.M. Tina, F. Pappalardo, Grid-connected photovoltaic system with battery 591 storage system into market perspective, (2009), Sustainable Alternative Energy 592 (SAE), 2009 IEEE PES/IAS Conference on, 1-7.

593 [5] M. Braun, K. Büdenbender, D. Magnor, A. Jossen, Photovoltaic Self594 Consumption in Germany - Using Lithium-Ion Storage to Increase Self595 Consumed Photovoltaic Energy, (2009), Proceedings of the 24th European 
596 Photovoltaic Solar Energy Conference, Hamburg, Germany, 21-25 September

$5972009,3121-3127$.

598 [6] D. Jenkins, J. Fletcher, D. Kane, Lifetime prediction and sizing of lead-acid 599 batteries for microgeneration storage applications, IET Renewable Power

600 Generation 2 (2008) 191-200.

601 [7] M.C. McManus, Environmental consequences of the use of batteries in low 602 carbon systems: The impact of battery production, Appl. Energy 93 (2012) 288603295.

604 [8] Ofgem, Scheme Tariff Tables, (2012), 605 http://www.ofgem.gov.uk/Sustainability/Environment/fits/tariff606 tables/Pages/index.aspx.

607 [9] British Gas, Gas \& electricity prices. Accessed: 15 Jun 2012 , (2012), 608 www.britishgas.co.uk.

609 [10] J.D. Mondol, Y.G. Yohanis, B. Norton, Optimising the economic viability of 610 grid-connected photovoltaic systems, Appl. Energy 86 (2009) 985-999.

611 [11] J. Keirstead, Behavioural responses to photovoltaic systems in the UK 612 domestic sector, Energy Policy 35 (2007) 4128-4141.

613 [12] A.R. Landgrebe, S.W. Donley, Battery storage in residential applications of 614 energy from photovoltaic sources, Appl. Energy 15 (1983) 127-137.

615 [13] SMA Solar Technology AG, Sunny Backup Set S, Accessed: 13 Aug 2012 , 616 (2012), http://www.sma.de/en/products/backup-systems/sunny-backup-set-s.html.

617 [14] Renewable Solutions, Grid BuddyTM, Accessed: 13 Aug 2012 , (2012),

618 http://www.renewablesolutionsuk.com/which-technology/grid-buddy-3.

619 [15] D. Guasch, S. Silvestre, Dynamic Battery Model for Photovoltaic

620 Applications, Progress in Photovoltaics: Research and Applications 11 (2003)

621 193-206.

622 [16] J. Copetti, F. Chenlo, Lead/acid batteries for photovoltaic applications. Test 623 results and modelling, Journal of Power Sources 47 (1994) 109-118.

624 [17] N. Achaibou, M. Haddadi, A. Malek, Modeling of Lead Acid Batteries in PV 625 Systems, Energy Procedia 18 (2012) 538-544.

626 [18] I. Richardson, M. Thomson, D. Infield, C. Clifford, Domestic electricity use: 627 A high-resolution energy demand model, Energy Build. 42 (2010) 1878-1887.

628 [19] J. Stevens, G. Corey, A Study of Lead-Acid Battery Efficiency Near Top-of629 Charge and the Impact on PV System Design, (1996), Conference Record of the 
630 Twenty Fifth IEEE Photovoltaic Specialists Conference

631 , Albuquerque, NM, 13-17 May 1996, 1485-1488.

632 [20] BP Solar, PVstor Batteries: Product Manual, (2001).

633 http://www.bp.com/liveassets/bp_internet/solar/bp_solar_australia/STAGING/loc

634 al_assets/downloads_pdfs/a/Aust_ps_solar_PVStor.pdf

635 [21] M. Munzinger, F. Crick, E. Dayan, N. Pearsall, C. Martin, PV Domestic

636 Field Trial: Final Technical Report, (2006).

637 [22] M. Š́uri, T.A. Huld, E.D. Dunlop, H.A. Ossenbrink, Potential of solar 638 electricity generation in the European Union member states and candidate 639 countries, Solar Energy 81 (2007) 1295-1305.

640 [23] D. Ton, C. Hanley, G. Peek, J. Boyes, Sandia Report: Solar Energy Grid 641 Integration Systems - Energy Storage (SEGIS-ES), (2008).

642 [24] Suka Sol, Inverter SMA Sunny Backup Unit 5000. Accessed 31 October 643 2012, (2012), http://www.sukasol.co.uk.

644 [25] Wholesalesolar, Inverter SMA Sunny Backup Unit 5000. Accessed 31 645 October 2012, (2012), http://www.wholesalesolar.co.uk/inverter-sunny-backup646 unit-5000-p-5017.html.

647 [26] Critical Power Supplies Ltd., SMA Sunny Backup 5 kW. Accessed 31 Oct 648 2012, (2012), http://www.criticalpowersupplies.co.uk/SMA-Sunny-Backup-5kW.

649 [27] ISO, Environmental management - life cycle assessment - principles and 650 framework, International Standards Organization Second Edition. EN ISO 65114040 (2006).

652 [28] ISO, Environmental management - life cycle assessment - requirements 653 and guidelines, International Standards Organization EN ISO 14044 (2006).

654 [29] M.J. Goedkoop, R. Heijungs, M. Huijbregts, A. De Schryver, J. Struijs, R. 655 Van Zelm, ReCiPe 2008: A Life Cycle Impact Assessment Method which 656 Comprises Harmonised Category Indicators at theMidpoint and the Endpoint 657 Level, VROM, Den Haag, The Netherlands Report 1: Characterisation, First 658 Edition (2009).

659 [30] T.E. Graedel, On the Future Availability of the Energy Metals, Annu. Rev. 660 Mater. Res. 41 (2011) 323-335.

661 [31] A.D. Hawkes, Estimating marginal CO2 emissions rates for national 662 electricity systems, Energy Policy 38 (2010) 5977-5987.

663 [32] Elexon, Balancing Mechanism Reports, Accessed: 10 Jun 2012 , (2011), 664 http://www.bmreports.com/. 
665 [33] EcoInvent, EcoInvent database, Accessed: 17 Aug 2012 , (2012),

666 http://www.ecoinvent.org/database/.

667 [34] German Federal Law, Tariffs and sample degression rates pursuant to the 668 new Renewable Energy Sources Act (Erneuerbare-Energien-Gesetz - EEG) .of 25

669 October 2008 with amendments of 11. August 2010, (2010).

670 [35] Queensland Government, Solar Bonus Scheme, Accessed: 2012, (2012),

671 http://www.cleanenergy.qld.gov.au/demand-side/solar-bonus-

672 scheme.htm?utm_source=CLEANEENERGY\&utm_medium=301\&utm_campaig

673 n=redirection.

674 [36] Department of Primary Industries, Feed-in Tariffs, Accessed: 2012 , (2012), 675 http://www.dpi.vic.gov.au/energy/environment-and-community/feed-in-tariffs.

676 [37] Department of Finance, Residential Feed-in tariff scheme, Accessed: 2012 , 677 (2012), http://www.finance.wa.gov.au/cms/content.aspx?id=14713.

678 
680 Table 7 - Weighted average change in electricity generated by coal to unit changes in total electrical demand 681 in GB electricity market (data from 2009 to 2011).

\begin{tabular}{|r|r|r|r|r|r|r|}
\hline $\begin{array}{r}\text { Hour } \\
\text { of day }\end{array}$ & \multicolumn{7}{|c|}{ Period of year } \\
\hline & 0 & 1 & 2 & 3 & 4 & 5 \\
\hline 0 & 0.494551 & 0.455457 & 0.437542 & 0.393212 & 0.396758 & 0.478689 \\
\hline 1 & 0.496866 & 0.469524 & 0.422298 & 0.368692 & 0.399714 & 0.510903 \\
\hline 2 & 0.500799 & 0.464754 & 0.440178 & 0.385595 & 0.398715 & 0.50572 \\
\hline 3 & 0.5489 & 0.432157 & 0.36836 & 0.363328 & 0.379169 & 0.514606 \\
\hline 4 & 0.566476 & 0.474136 & 0.452927 & 0.398794 & 0.502077 & 0.475355 \\
\hline 5 & 0.567946 & 0.555243 & 0.506174 & 0.460635 & 0.586774 & 0.559716 \\
\hline 6 & 0.52664 & 0.61185 & 0.618944 & 0.569299 & 0.627499 & 0.574908 \\
\hline 7 & 0.562577 & 0.617038 & 0.579624 & 0.585671 & 0.580824 & 0.606942 \\
\hline 8 & 0.54072 & 0.586075 & 0.558954 & 0.557762 & 0.613838 & 0.544663 \\
\hline 9 & 0.54419 & 0.550934 & 0.515535 & 0.533581 & 0.532024 & 0.556299 \\
\hline 10 & 0.527202 & 0.490187 & 0.522915 & 0.53868 & 0.542271 & 0.522832 \\
\hline 11 & 0.484315 & 0.562545 & 0.556201 & 0.550072 & 0.541937 & 0.53242 \\
\hline 12 & 0.491218 & 0.598059 & 0.557904 & 0.556898 & 0.547817 & 0.499456 \\
\hline 13 & 0.496241 & 0.604643 & 0.587941 & 0.534845 & 0.570576 & 0.512185 \\
\hline 14 & 0.527025 & 0.59763 & 0.582466 & 0.550426 & 0.587472 & 0.512683 \\
\hline 15 & 0.466498 & 0.604244 & 0.556948 & 0.531664 & 0.564756 & 0.505471 \\
\hline 16 & 0.509246 & 0.580713 & 0.590093 & 0.573185 & 0.59181 & 0.540284 \\
\hline 17 & 0.537683 & 0.611151 & 0.6338 & 0.607297 & 0.608505 & 0.51186 \\
\hline 18 & 0.53161 & 0.630377 & 0.637861 & 0.602651 & 0.62768 & 0.54301 \\
\hline 19 & 0.544557 & 0.57606 & 0.58905 & 0.586922 & 0.662873 & 0.477636 \\
\hline 20 & 0.543458 & 0.637469 & 0.565202 & 0.567295 & 0.638235 & 0.51867 \\
\hline 21 & 0.494102 & 0.650307 & 0.600947 & 0.592812 & 0.636466 & 0.560413 \\
\hline 22 & 0.518938 & 0.579318 & 0.482388 & 0.492356 & 0.537305 & 0.601915 \\
\hline 23 & 0.51428 & 0.481071 & 0.452315 & 0.390059 & 0.452874 & 0.556961 \\
\hline
\end{tabular}

682 
683 Table 8 - Weighted average response in electricity generated by gas (CCGT) to unit changes in total 684 electrical demand in GB electricity market (data from 2009 to 2011).

\begin{tabular}{|r|r|r|r|r|r|r|}
\hline $\begin{array}{r}\text { Hour } \\
\text { of day }\end{array}$ & \multicolumn{5}{|c|}{ Period of year } \\
\hline & 0 & 1 & 2 & 3 & 4 & 5 \\
\hline 0 & 0.505449 & 0.544543 & 0.562458 & 0.606788 & 0.603242 & 0.521311 \\
\hline 1 & 0.503134 & 0.530476 & 0.577702 & 0.631308 & 0.600286 & 0.489097 \\
\hline 2 & 0.499201 & 0.535246 & 0.559822 & 0.614405 & 0.601285 & 0.49428 \\
\hline 3 & 0.4511 & 0.567843 & 0.63164 & 0.636672 & 0.620831 & 0.485394 \\
\hline 4 & 0.433524 & 0.525864 & 0.547073 & 0.601206 & 0.497923 & 0.524645 \\
\hline 5 & 0.432054 & 0.444757 & 0.493826 & 0.539365 & 0.413226 & 0.440284 \\
\hline 6 & 0.47336 & 0.38815 & 0.381056 & 0.430701 & 0.372501 & 0.425092 \\
\hline 7 & 0.437423 & 0.382962 & 0.420376 & 0.414329 & 0.419176 & 0.393058 \\
\hline 8 & 0.45928 & 0.413925 & 0.441046 & 0.442238 & 0.386162 & 0.455337 \\
\hline 9 & 0.45581 & 0.449066 & 0.484465 & 0.466419 & 0.467976 & 0.443701 \\
\hline 10 & 0.472798 & 0.509813 & 0.477085 & 0.46132 & 0.457729 & 0.477168 \\
\hline 11 & 0.515685 & 0.437455 & 0.443799 & 0.449928 & 0.458063 & 0.46758 \\
\hline 12 & 0.508782 & 0.401941 & 0.442096 & 0.443102 & 0.452183 & 0.500544 \\
\hline 13 & 0.503759 & 0.395357 & 0.412059 & 0.465155 & 0.429424 & 0.487815 \\
\hline 14 & 0.472975 & 0.40237 & 0.417534 & 0.449574 & 0.412528 & 0.487317 \\
\hline 15 & 0.533502 & 0.395756 & 0.443052 & 0.468336 & 0.435244 & 0.494529 \\
\hline 16 & 0.490754 & 0.419287 & 0.409907 & 0.426815 & 0.40819 & 0.459716 \\
\hline 17 & 0.462317 & 0.388849 & 0.3662 & 0.392703 & 0.391495 & 0.48814 \\
\hline 18 & 0.46839 & 0.369623 & 0.362139 & 0.397349 & 0.37232 & 0.45699 \\
\hline 19 & 0.455443 & 0.42394 & 0.41095 & 0.413078 & 0.337127 & 0.522364 \\
\hline 20 & 0.456542 & 0.362531 & 0.434798 & 0.432705 & 0.361765 & 0.48133 \\
\hline 21 & 0.505898 & 0.349693 & 0.399053 & 0.407188 & 0.363534 & 0.439587 \\
\hline 22 & 0.481062 & 0.420682 & 0.517612 & 0.507644 & 0.462695 & 0.398085 \\
\hline 23 & 0.48572 & 0.518929 & 0.547685 & 0.609941 & 0.547126 & 0.443039 \\
\hline
\end{tabular}

685 
A. Charge voltage (upper four lines) and discharge voltage (lower four lines)

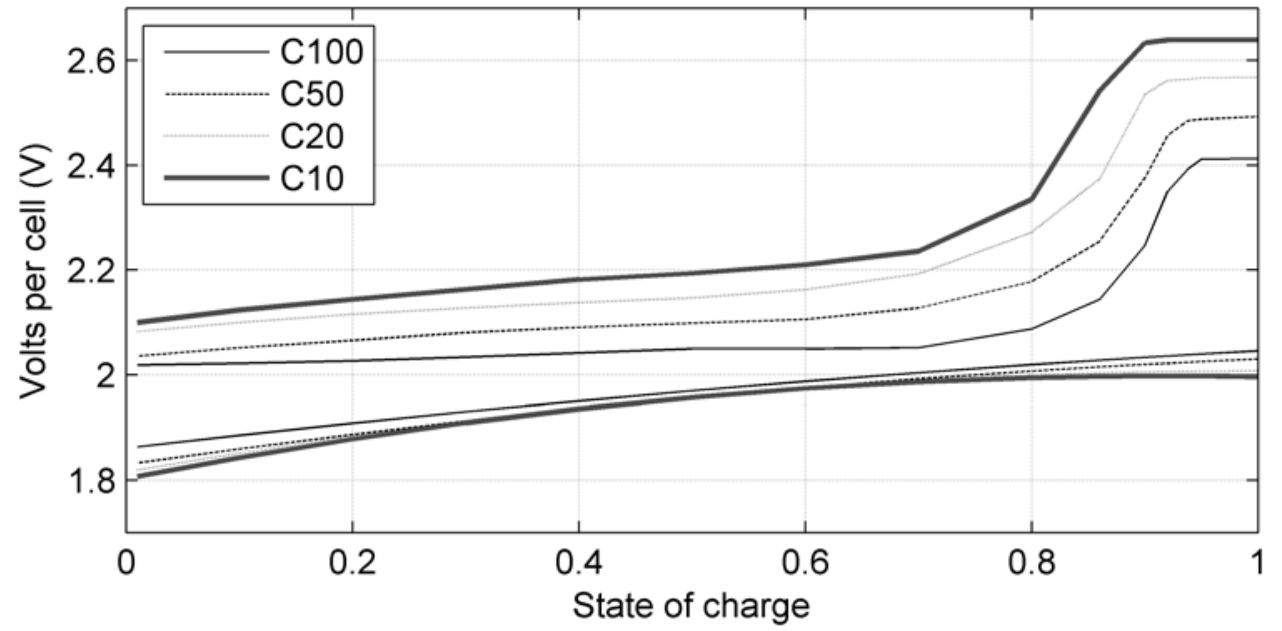

B. Voltage efficiency

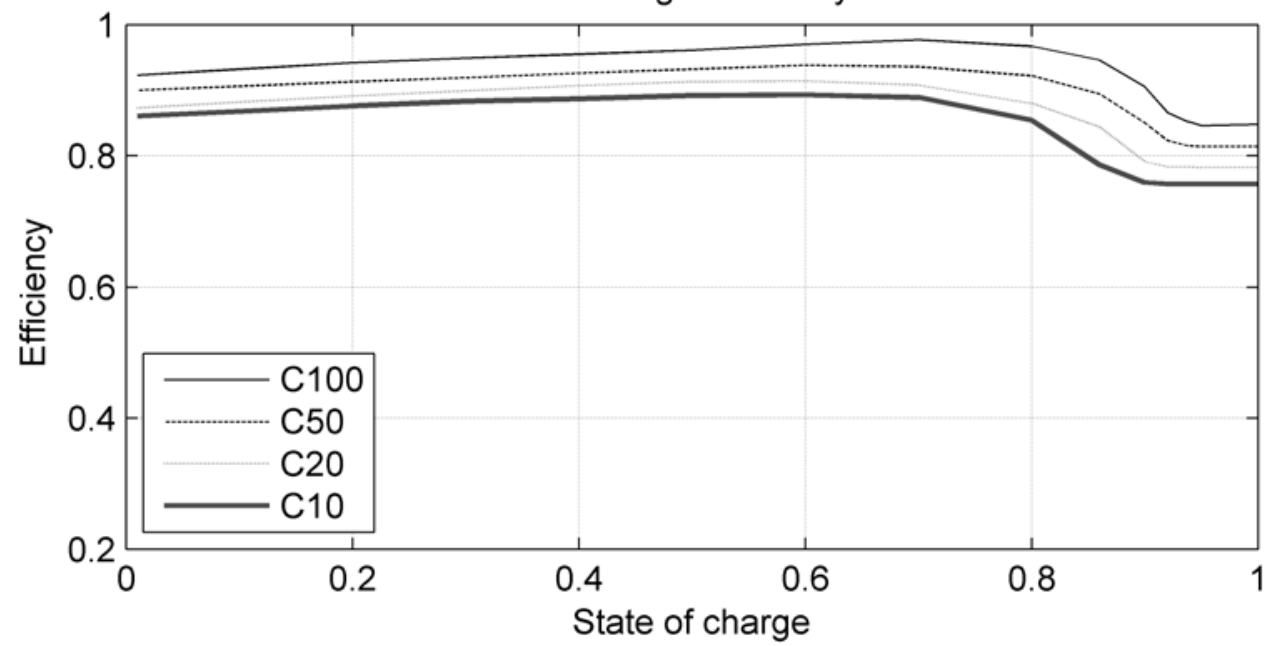

687

688 Figure 1 - Voltage efficiency used in the battery model.

689 


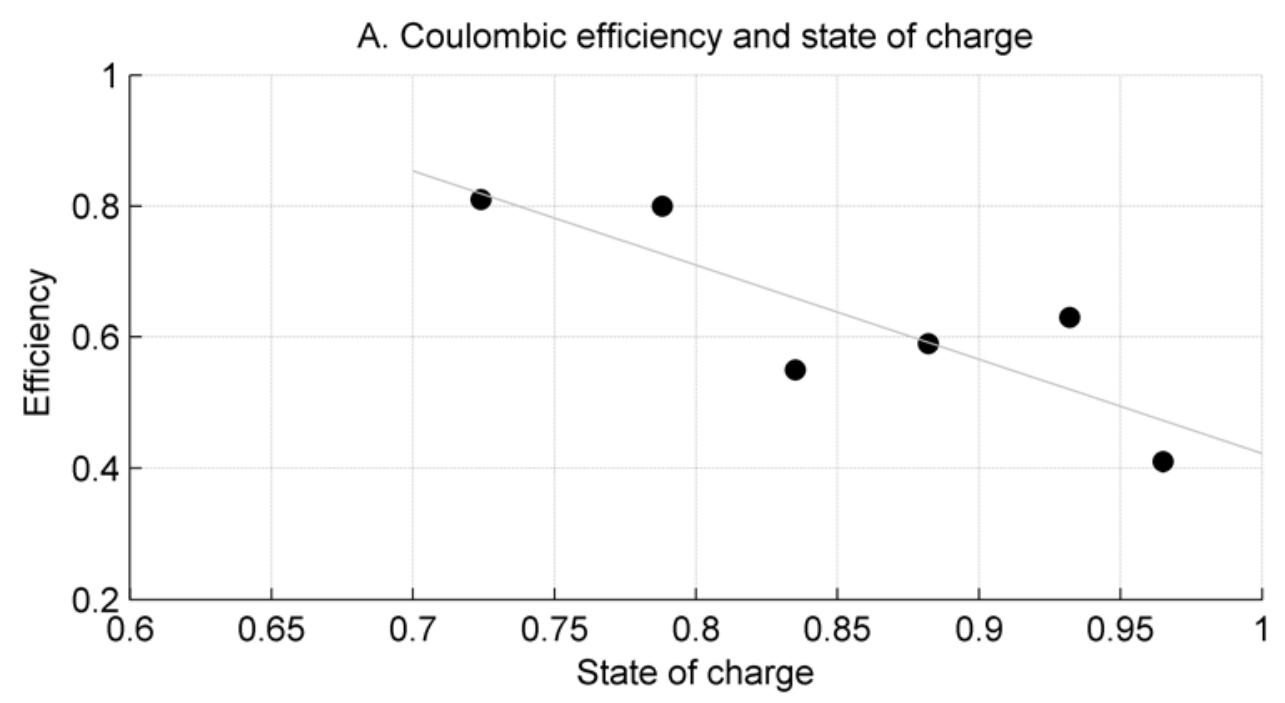

B. Coulombic efficiency and discharge current

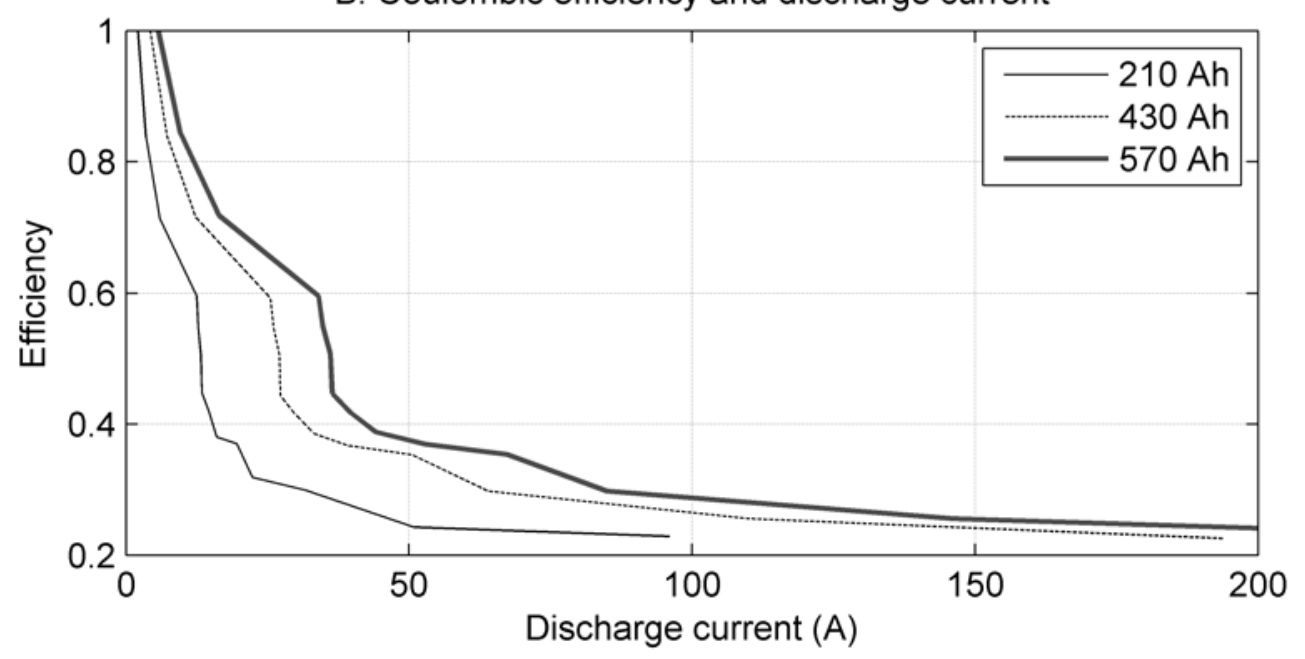

690

691 Figure 2 - Coulombic efficiency used in the battery model. 


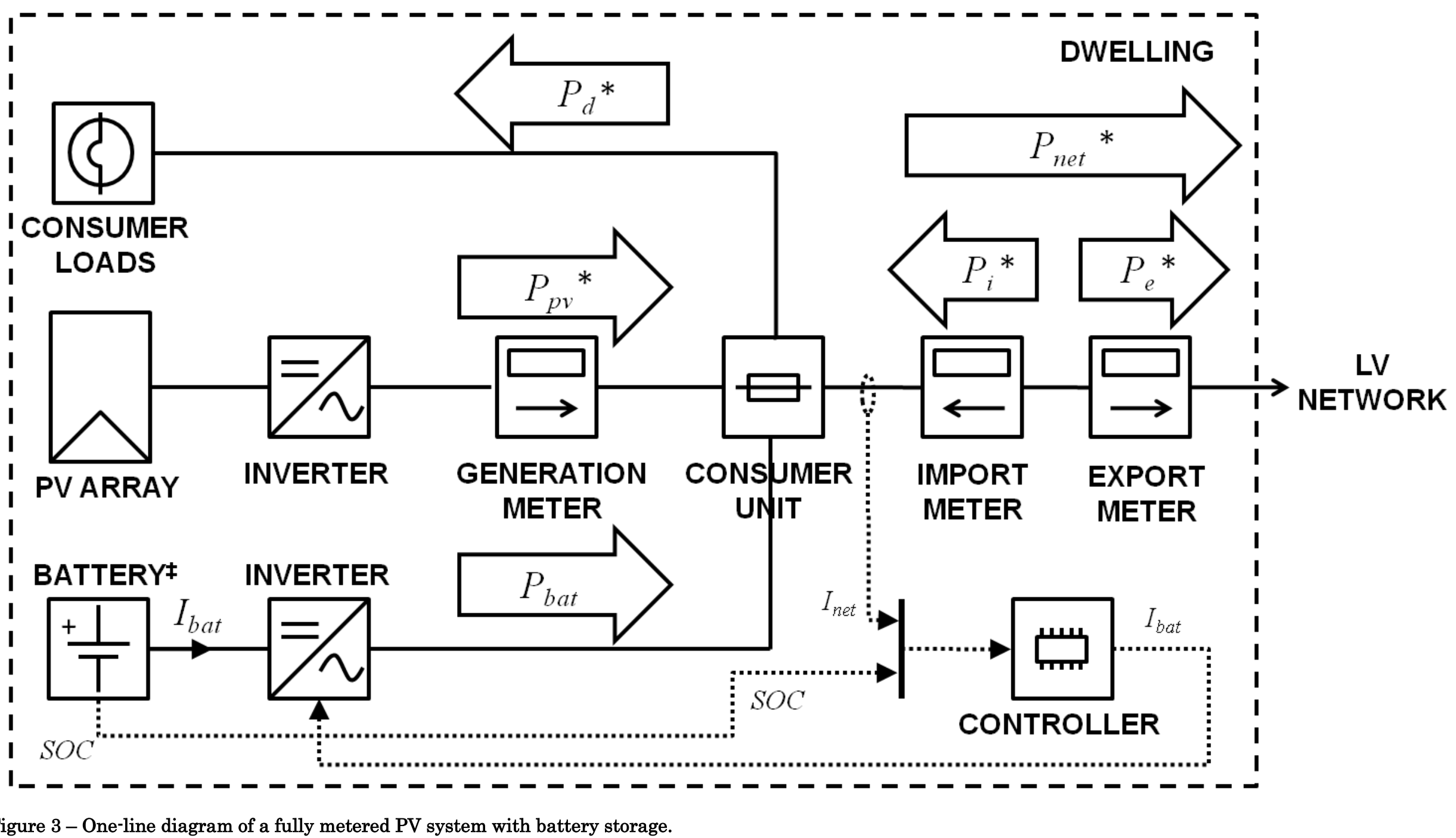

Figure 3 - One-line diagram of a fully metered PV system with battery storage. 
A. PV generation and electricity demand for a single dwelling on 15-Jun-2006

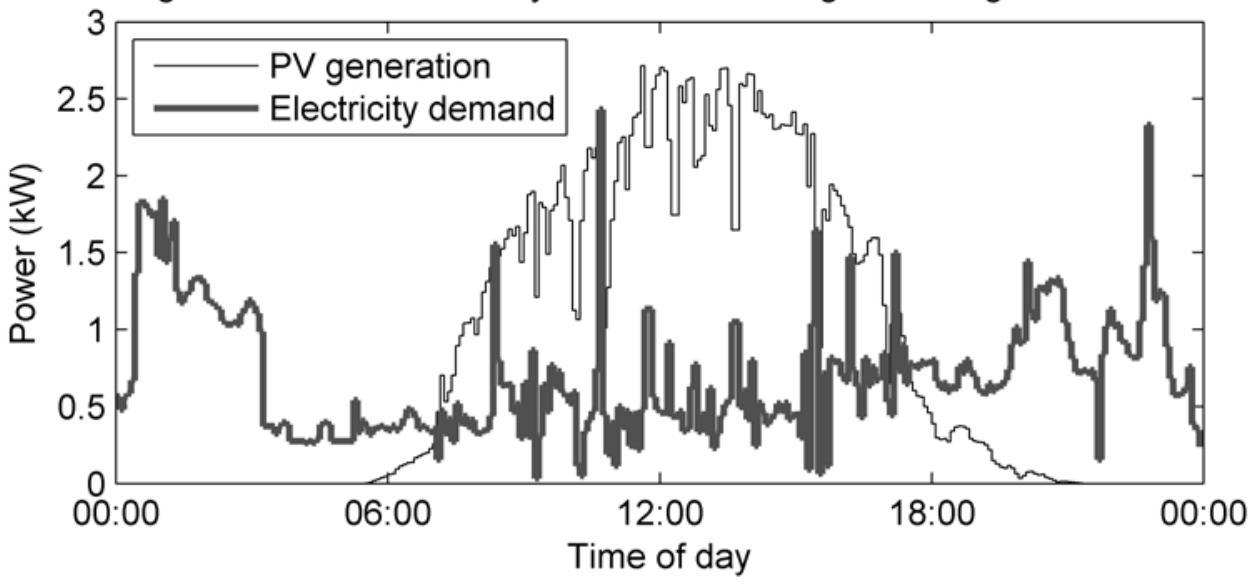

B. Net dwelling power flow. Exports are positive.

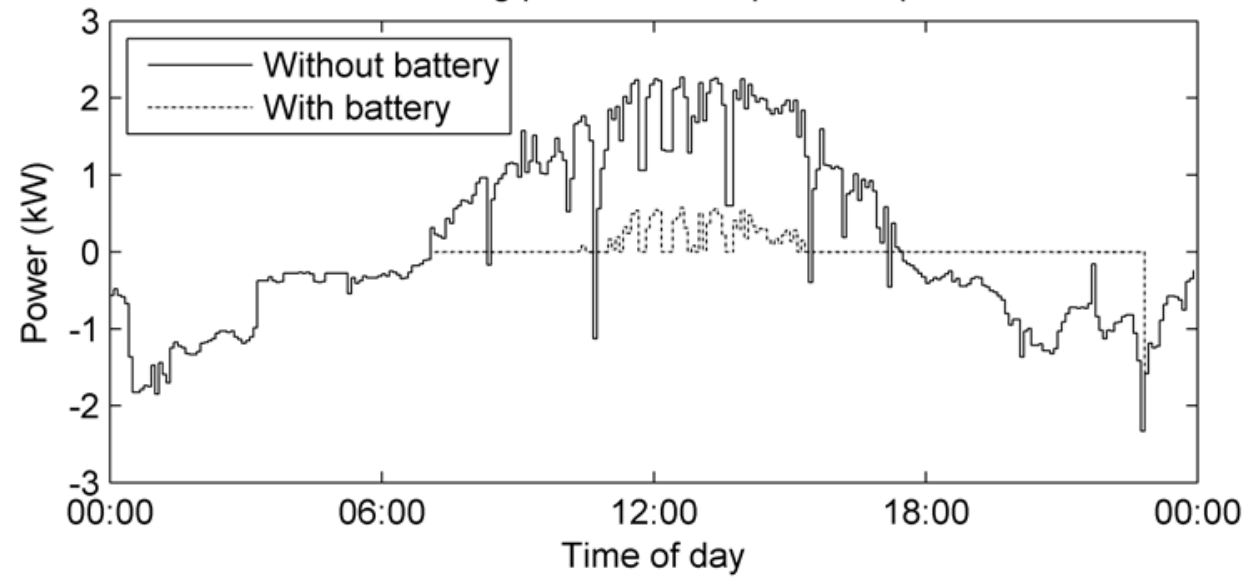

694

695 Figure 4-PV generation, dwelling demand, net power flow to the grid, before and after battery. 


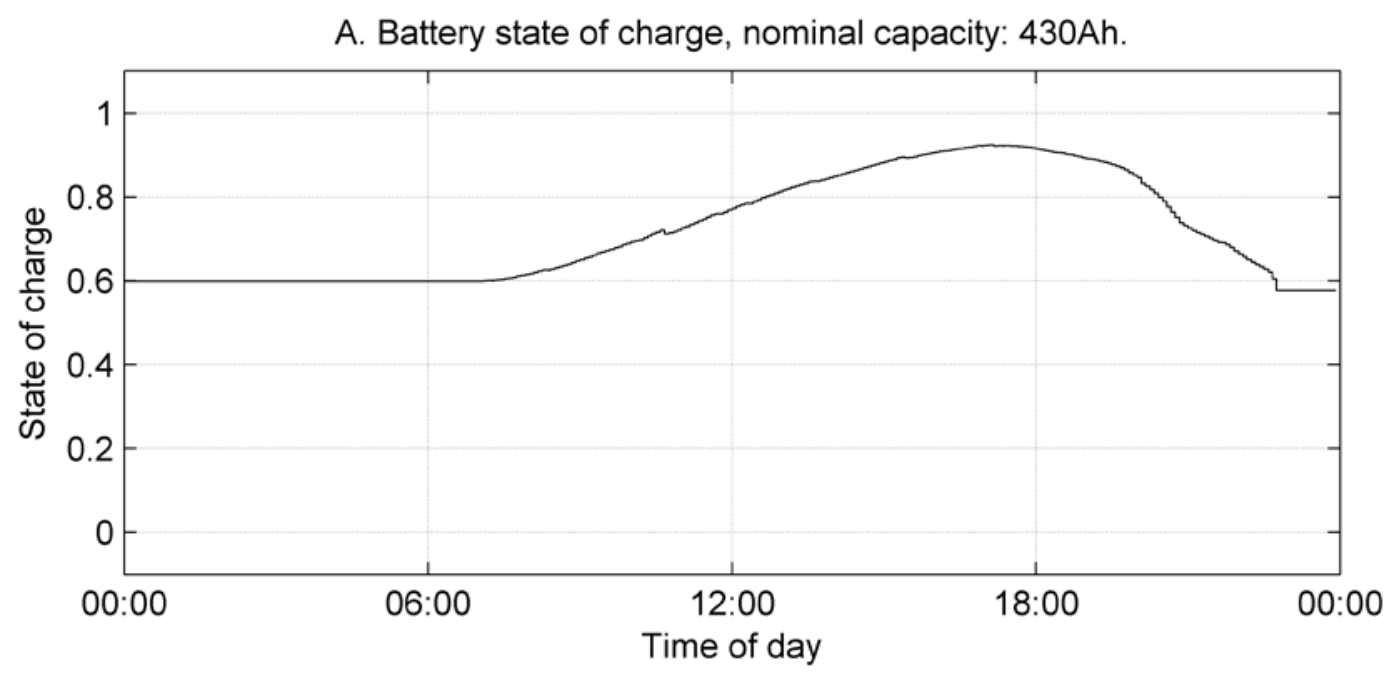

B. Battery efficiency.

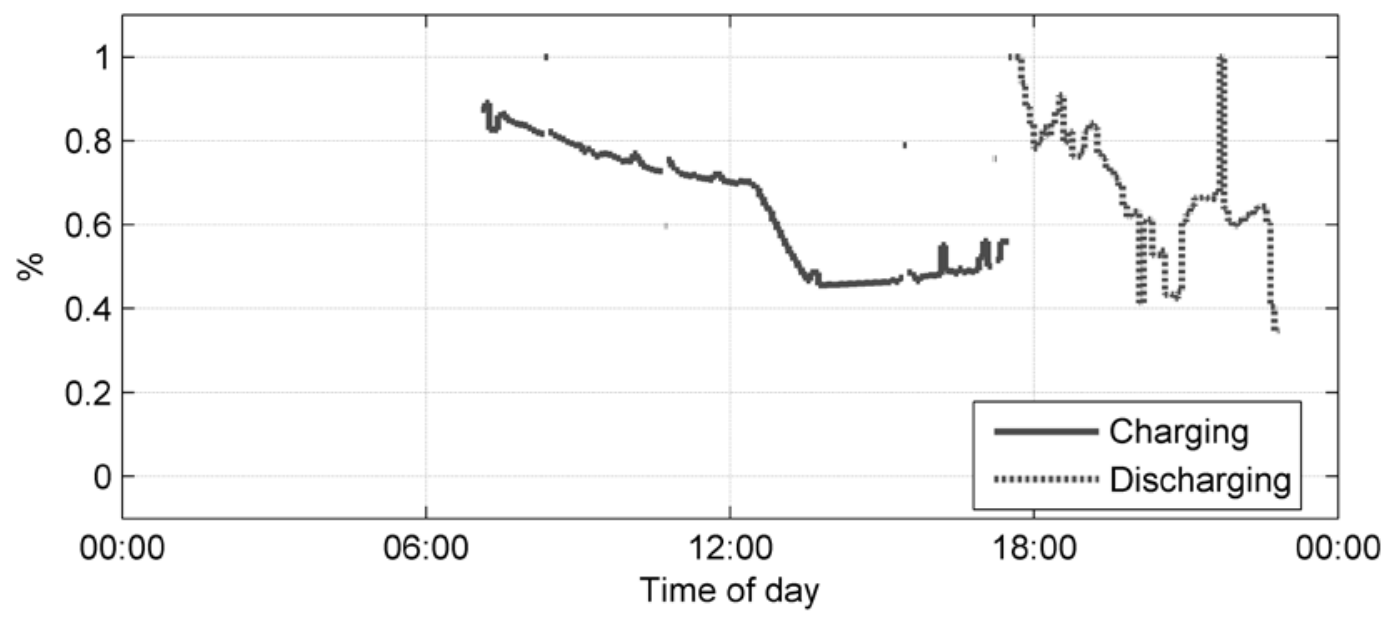

696

697 Figure 5 - Battery state of charge and efficiency. 

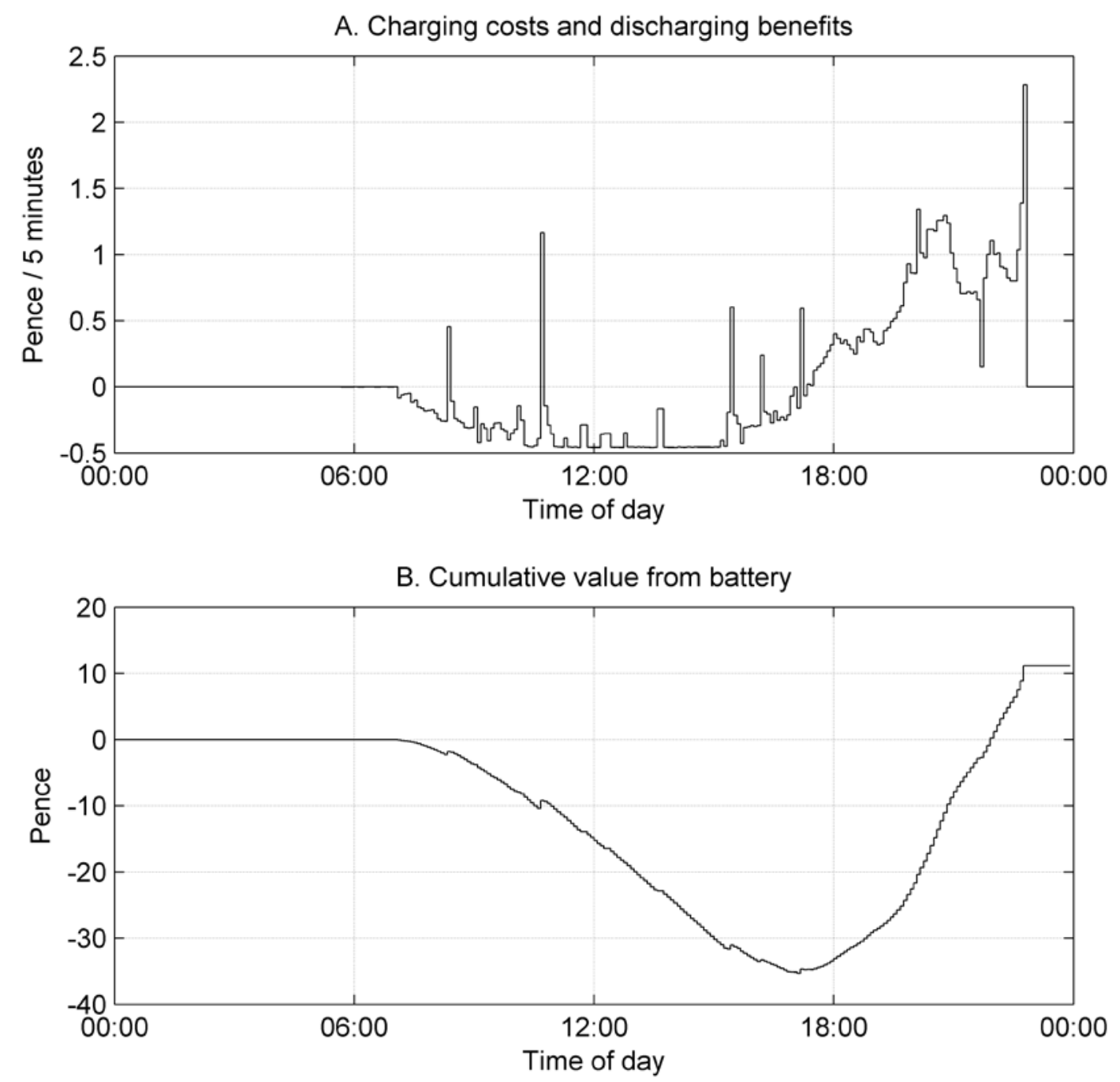

698

699 Figure 6-Cost benefit over the course of a single day. 


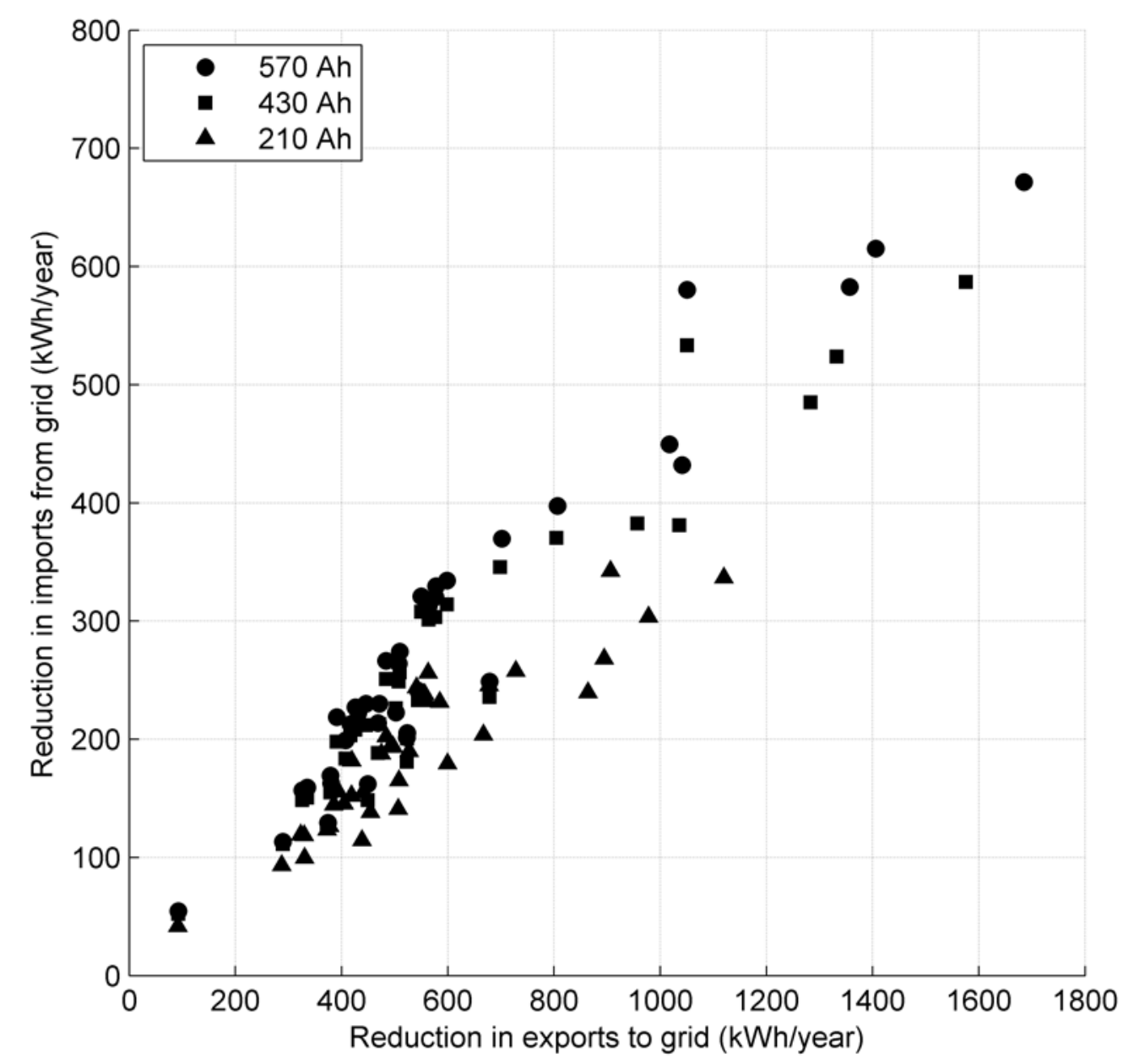

700

701 Figure 7 - Reduction in imports and exports associated with realistic batteries of various sizes for multiple 702 dwellings with PV in the UK. 


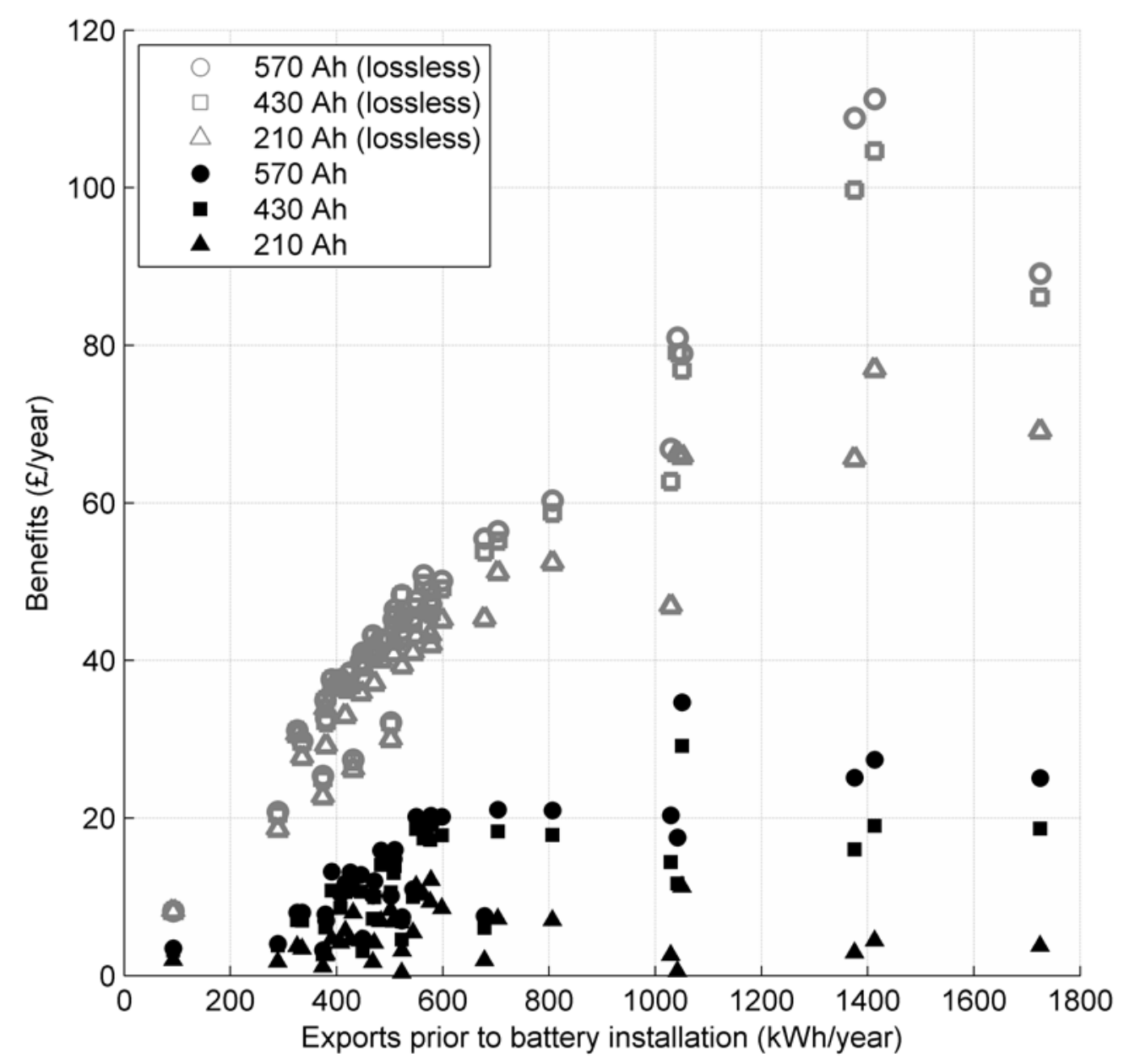

703

704 Figure 8 - Annual benefits for lossless and realistic batteries for multiple dwellings with PV in the UK. 

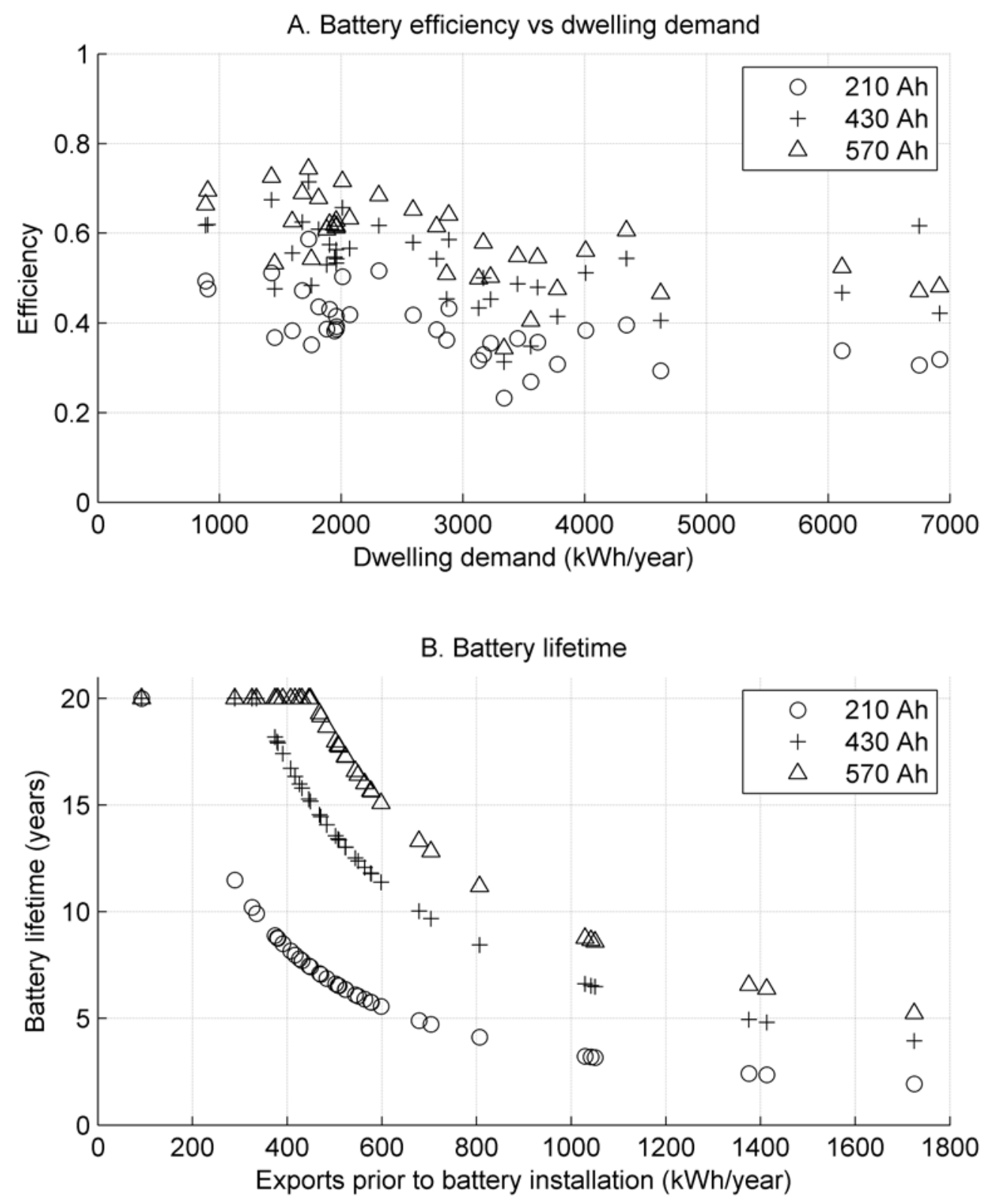

705

706 Figure 9-Battery round-trip efficiency and lifetime. 


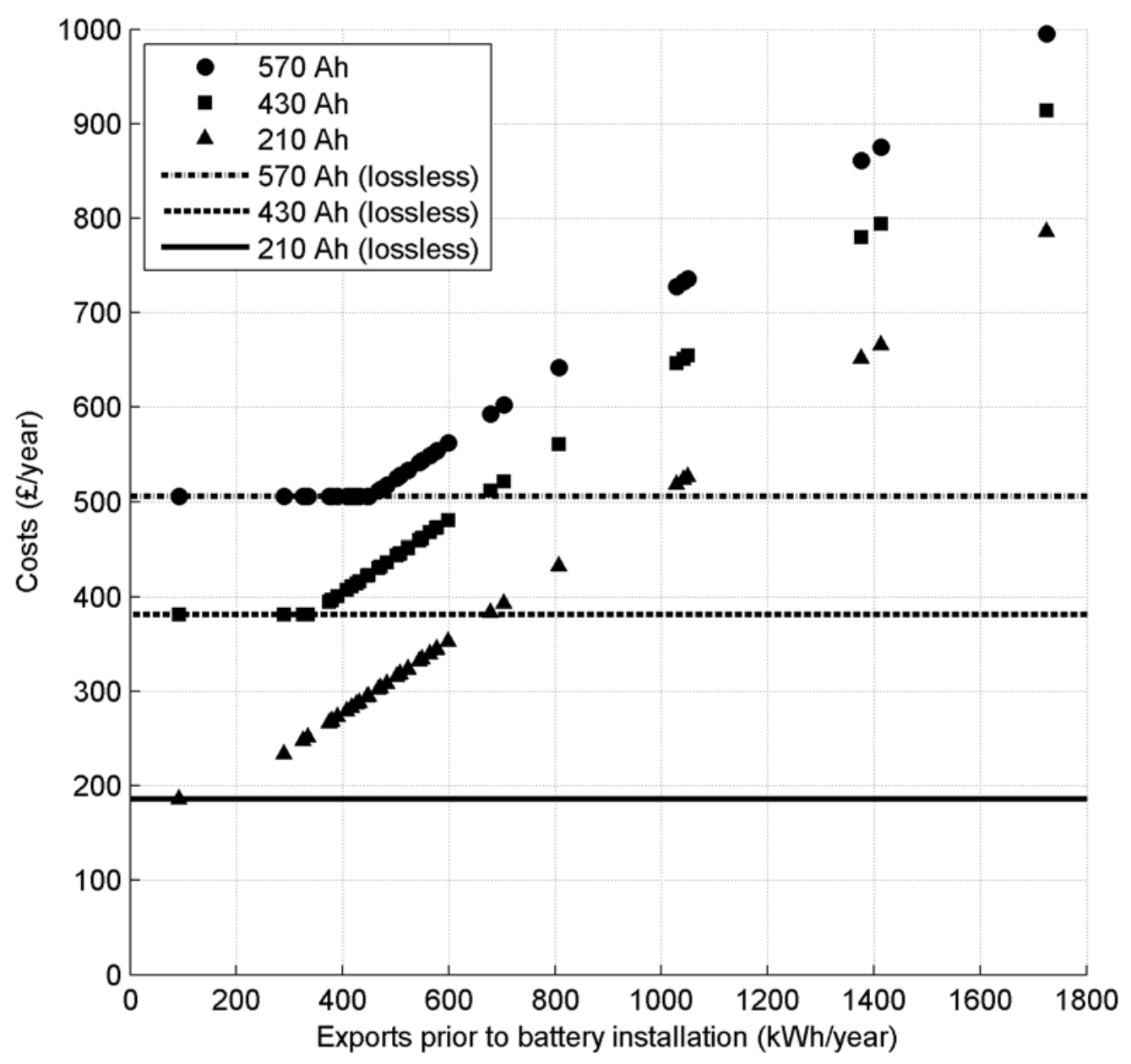

707

708 Figure 10 - Annual costs for lossless and realistic batteries for multiple UK dwellings with PV. 


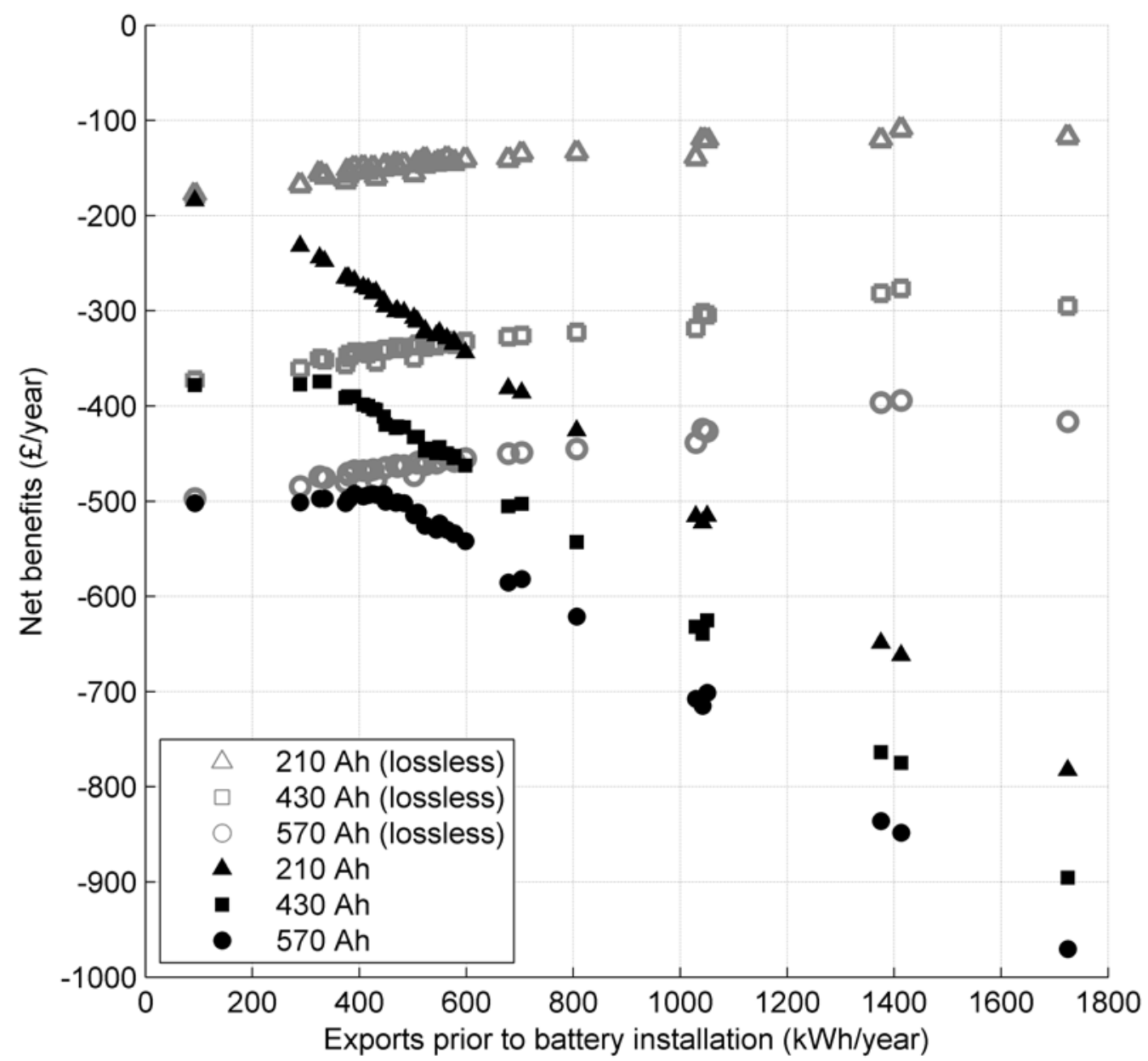

709

710 Figure 11 - Annual net benefits for lossless and realistic batteries for multiple dwellings with PV in the UK. 


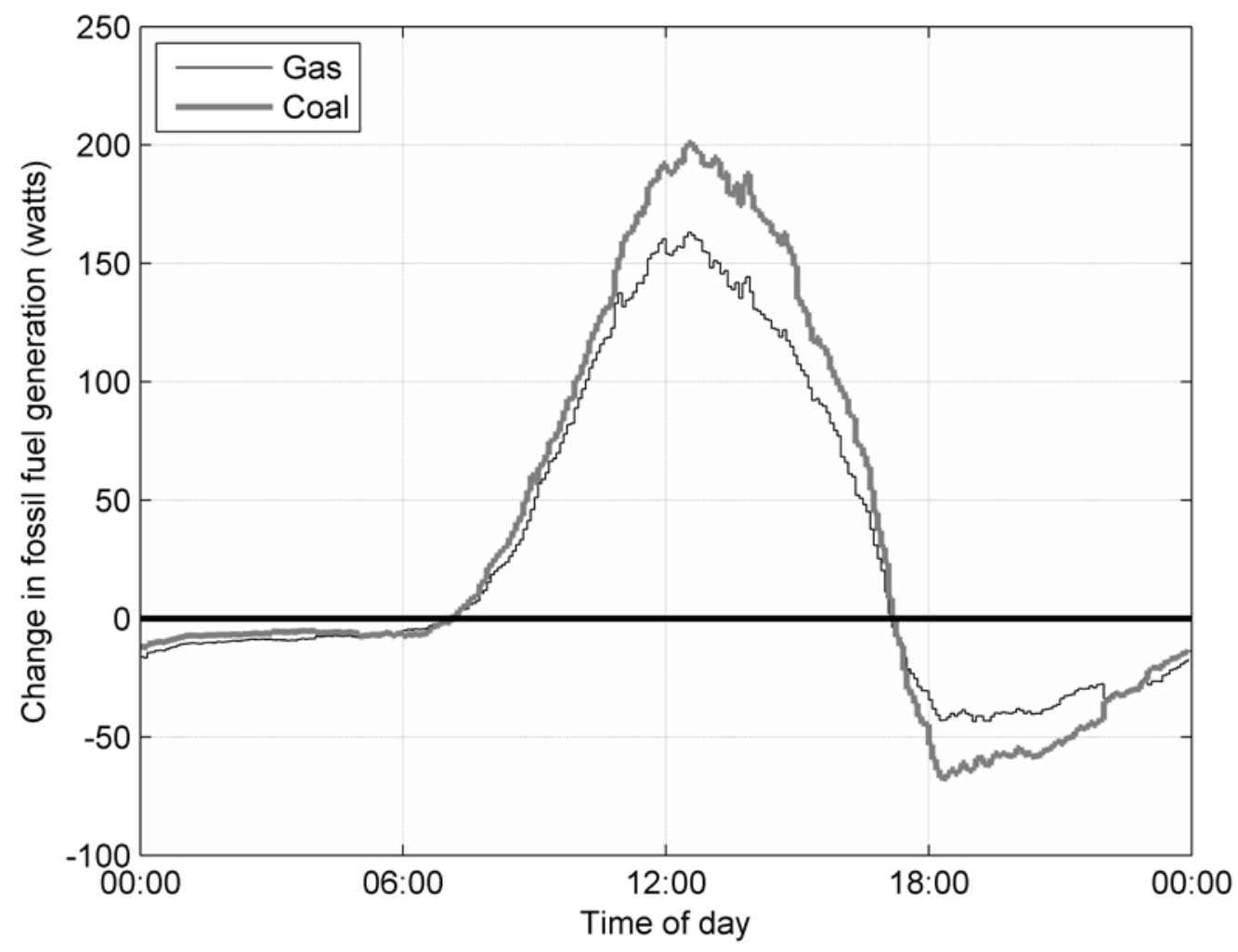

711

712 Figure 12 - Change in fossil fuel generation caused by the operation of a realistic $430 \mathrm{Ah}$ battery averaged 713 over the whole year and the multiple dwellings considered here.

714

715 